\title{
Energy flow in progressive collapse of steel framed buildings
}

\author{
Stefan Szyniszewski ${ }^{\mathrm{a} 1}$, Ted Krauthammer ${ }^{\mathrm{b}}$ \\ ${ }^{a}$ Bechtel Power Corporation, US Nuclear Projects, Frederick, MD 21703 \\ ${ }^{\mathrm{b}}$ Dept. of Civil and Coastal Engineering, University of Florida, Gainesville, FL 32611
}

\begin{abstract}
This paper provides the methodology for an energy-based progressive collapse assessment of multistory buildings. The progressive collapse of steel-framed buildings is analyzed based on an energy flow perspective. The energy based assessment of structural members is introduced, and compared with conventional force and deformation approaches discussed in the literature. Consecutively, the advantages of energy flow analysis in interpretation of extreme dynamic events are discussed. On the global level, a building can arrest the collapse, and achieve its stable configuration only if the kinetic energy is completely dissipated by the structure. Otherwise, the remaining kinetic energy will cause the collapse to continue. In a conventional building, kinetic energy is dissipated within structural members by the transformation into their deformation energy. Structural members can dissipate finite amounts of energy before becoming unstable. The column deformation energy was shown to be a better stability indicator under dynamic loading than the maximum dynamic force. The energy flow analysis is illustrated with a collapse assessment of a typical steel building.
\end{abstract}

Keywords: progressive collapse, energy flow, energy dissipation, structural robustness, steel building, global stability, column buckling, collapse analysis

\footnotetext{
${ }^{1}$ Corresponding author: 5275 Westview Drive, Building FR1-3H2 Suite 300, Frederick, MD, 21703. s.szyniszewski@gmail.com
} 


\section{Introduction}

Civil engineering practices evolved over times when disproportionate collapse attracted little attention. Progressive collapse resistance was not a design consideration until the Ronan Point building collapsed in 1968 [1]. Consequently, structural layouts and designs of typical buildings reflect an investment in technology not ideally suited to resist disproportionate collapse. Unfortunately, the Murrah Federal Building collapse proved that the possibility of progressive, catastrophic failure is remarkably real and must be addressed [2]. An increasing number of buildings are locally damaged due to explosions and construction errors. Progressive failure can potentially spread throughout the building and result in a catastrophic failure that involves numerous deaths $[3,4,5,6]$. This study aims at providing new insights into the dynamic, transient phase of collapse propagation. The main objective of this work is to enable the development of an energy-based analysis of progressive collapse of steel buildings by focusing on the role of the energy flow. The specific objectives are:

- Compare the energy flow method to traditional force-based approaches, and demonstrate their equivalence in well-understood situations,

- Provide an illustrative example of how to interpret and employ the energy-based analysis of progressive collapse.

\section{Background}

Progressive collapse can be viewed as a "domino effect" because a local failure triggers successive failures, progressing in time to a collapse encompassing a disproportionately large portion of a building. The in-depth overview of progressive collapse mitigation approaches and robustnessoriented design can be found in [7]. Grierson et al. [8] proposed an incremental, sequential static procedure. Grierson's method is an extension of a plastic hinge approach. Each step of the procedure ends at the formation of a new set of plastic hinges until the building collapses or reaches a stable state. This approach includes connection failure and accounts for impact forces from falling members. 
Izzuddin et al. [9] focused on connections between beams and columns as triggers of partial or total collapse. However, not only connections may lead to collapse propagation, but also column buckling may initiate a total collapse in typical steel structures. Schafer and Bajpai [10] proposed that the number of members "removed" from a structure leading to a loss of building stability (under gravity loads) may be used for quantification of building robustness. Gradual stability degradation due to member removals was presented in a probabilistic fragility framework borrowed from seismic engineering.

Kaewkulchai and Williamson [11] demonstrated that a static analysis may not provide conservative estimates of the collapse potential. This is important given that most current design codes recommend the Alternate Load Path Method. It is a static approach for determining whether or not a structure is likely to collapse following the failure of a key component. However, Kaewkulchai and Williamson's results indicated that the dynamic redistribution of loads is a significant feature of the progressive collapse. Although, a dynamic simulation requires more effort to represent the mass distribution, geometric and material nonlinearities, only this approach can provide a complete insight into building resistance to a disproportionate collapse $[10,11,12]$. A sudden removal of columns inevitably results in a dynamic, transient response, possibly cyclic loading, and plastic deformations. Such dynamic loads degrade material properties, increase existing imperfections and diminish the structural reserve capacity.

The formulations of non-linear relationships interpreting equilibrium, geometric compatibility and constitutive models, and their discretizations to numerical solutions are still a challenge in engineering mechanics research. Menchel et al. [14] discussed a number of collapse simulation techniques. Moment resisting steel frames have been analyzed in recent years using finite element codes such as ABAQUS and LS-DYNA [12]. One, two, or three columns at the ground level were instantaneously removed from a 10-story building following the quasi-static application of gravity, dead and live loads. Khandelwal et al. [15][16] carried out numerical simulations of 2-D steel frames in order to evaluate two selected bracing 
systems with regard to their progressive collapse resistance. Sadek et al. [17] have also investigated numerical modeling of steel structures under sudden column loss, with special emphasis on slabs and moment connection modeling. More recently, Kwasniewski [18] described high resolution dynamic simulations of progressive collapse following a sudden column removal.

A number of researchers have shifted their attention to energy as the key in understanding the dynamics of progressive collapse. Energy based approaches were explored long before the interest in progressive collapse resurfaced in structural engineering community. Love[22] analytically described the flux of energy in vibratory motion without resorting to notions of stress and strain. Xing and Price [23] developed a mathematical model to describe the power flow in a continuum with energy terms only. Szyniszewski et al. [19][20] showed the importance of deformation energy in the context of progressive collapse. Smyth and Gjelsvik [21] proposed that column axial capacity should be evaluated using the deformation work done by external forces. Energy considerations are also the main criteria in planning the demolitions, sequencing of detonations and determining the weight of explosives [22]. Bažant and Verdure [23] showed that progressive collapse is triggered if energy dissipated by the complete crushing of one story, minus the loss of gravity potential during the crushing of that story, is exceeded by the kinetic energy impacted to that story. Seffen [24] independently proposed a one-dimensional collapse model of the World Trade Center towers, which is in essence equivalent to the Bažant and Verdure approach.

\section{Research approach}

Some of the most important information concerning the progressive collapse is gained by surveying the performance of structures which have been subjected to localized damage [25]. However, these tragic events taking place in the real world are seldom planned to maximize the value of the 
information gained. Thus, numerical simulations, employing dynamic, non-linear finite element method LS-DYNA [26], were carried out in order to explore the energy flow during progressive collapse.

A three story steel framed building, utilized in SAC seismic study by Gupta and Krawinkler [27], and in progressive collapse research by Foley et al. [28] was investigated. The analyzed structure represents a typical low rise seismic steel building in US. All prevailing requirements for gravity, wind, and seismic design were considered. It was designed for a typical office occupancy live load of $2.5 \mathrm{kPa}$. The floors were assumed to support a dead load of $4 \mathrm{kPa}$, which included a concrete-steel composite slab, steel decking, ceilings /flooring /fireproofing, mechanical /electrical/ plumbing systems and partitions (1 kPa). The framing plan of the investigated 3-story building is shown in Figure 1, and the building layout in Table 1. Column schedules are given in Table 2 with designations in accordance with AISC [29].

\subsection{Energy flow}

Energy definitions are introduced herein for the sake of clarity. External work is the work done by applied forces, i.e. by gravity accelerations acting on the structural mass. Gravity forces do the external work via building displacements. The total flow of energy into a system (external work) must equal the total amount of energy in the system (sum of internal and kinetic energy). Internal energy (deformation work) was calculated using the following definition:

$$
E_{\text {int }}=\int\left(\int \sigma d \varepsilon\right) d V
$$

The total strain can be decomposed into elastic (recoverable) and plastic (irrecoverable):

$$
d \varepsilon=d \varepsilon^{e}+d \varepsilon^{p}
$$

$d \varepsilon^{e}=$ elastic strain increment, $d \varepsilon^{p}=$ plastic strain increment.

Internal energy includes elastic strain energy and work done in permanent deformations:

$$
E_{\mathrm{int}}=\int\left(\int \sigma d \varepsilon\right) d V=\int\left(\int \sigma d \varepsilon^{e}\right) d V+\int\left(\int \sigma d \varepsilon^{p}\right) d V
$$


$\int\left(\int \sigma d \varepsilon^{e}\right) d V=$ elastic strain energy, $\int\left(\int \sigma d \varepsilon^{p}\right) d V=$ permanent deformation work.

However, not only deformation (internal energy) results from external work done on a system. If a beam falls with a velocity $v$, the external work (done by gravity) results in kinetic energy but no strains and thus no internal energy (no deformation) is induced in the system. During a collapse, however, there are both deformations and rigid motions, kinetic energy. Kinetic energy was reported using the following definition:

$$
E_{k i n}=\int \frac{1}{2} \rho v^{2} d V
$$

$\rho=$ mass density, $v=$ particle velocity.

\subsection{Structural representation}

A large strain, piecewise linear, material model 24 from the LS-DYNA [26] library was employed to represent large strain steel material behavior. Model 24 operates on true stress and logarithmic strain measures, thus it accounts for large strains. Strength enhancement associated with high speed loading is typically not included in the material modeling because gravity driven, sudden load release is not in the regime of explosive loading. Application of gravity loading following localized failure occurs over hundreds of ms, which is 2-3 orders of magnitude slower than explosive loading rates taking place in ms. Hughes-Liu beam elements, with plasticity and large deformation capabilities, were utilized to model the steel frame of the investigated steel building. The Hughes-Liu formulation is incrementally objective (rigid body rotations do not generate strains). Thus, it is suitable for simulations characterized by large strains and displacement. It also includes finite transverse shear strains. Both beam and column elements are capable of exhibiting a variation of strains and their corresponding stresses through the section. Thus, the Hughes-Liu formulation was able to model yield propagation through the section. Material failure was controlled by the prescribed value of the effective plastic failure strain. The element 
was deleted, when the average effective plastic strain of nine integration points was greater than the critical, prescribed value.

A lightly reinforced slab was employed in this study, and represented as a $100[\mathrm{~mm}]$ thick shell with the custom integration scheme. Steel material model was used for the bottom layer; whereas other layers were modeled using concrete material properties. An important structural element for the analysis of progressive collapse is the beam-column joint. Connections were represented with macro-models consisting of non-linear spring elements. The properties of the springs were calibrated against the authors' high-resolution finite element simulations published elsewhere [30][31], and available experimental tests [17][32]. Spring representation is computationally efficient, yet it adequately captures the connection behavior. This approach is consistent with alternative macro-model methods [15].

Due to the lack of published full-scale experiments, a limited in scope two-dimensional experimental verification was carried out. The U.S. Army Engineer Research and Development Center test results, presented by Sadek [17], were used to validate the Hughes-Liu representation of the structural frame. A two-dimensional frame (comprising of columns, beams and moment resisting connections) was loaded up to failure (Figure 2). The simulation approach to the structural frame was compared with the experimental results in Figure 3. The numerical simulations captured the non-linear frame resistance with great realism. It should be noted that typically employed rigid moment connections provided a ductility beyond the actual experimental connection capacities. Good agreement between experimental and numerical results validated the ability of the simulation to represent the actual plastic behavior of the steel frame under extreme loading. In the future, this approach may need to be refined, as more experimental data from tests of three-dimensional steel buildings, including slabs, become available. 


\subsection{Localized damage}

Liu et al. [33] investigated the effect of the column removal time on displacement of a 3 story building. The time taken to completely remove the column affected the structural response. However, their data had also shown that when a column removal time reached a certain rate, such as $10 \mathrm{~ms}$ for the considered building, the final results did not differ noticeably from the $1 \mathrm{~ms}$ case. Pressure and shock waves generated by explosions last at most several ms. Thus, instantaneous column removal is an accurate approach in capturing post-blast structural response because the structure is not sensitive to the removal time at this rate regime. However, a typical blast event is also expected to cause extensive damage to adjacent elements. These more realistic conditions tend to be ignored in current progressive collapse guidelines, and will not be addressed herein.

\subsection{Dynamic building response}

A collapse phase was characterized by large deflections, pronounced material non-linearities and contact between members. The finite element code LS-DYNA [26] was chosen to perform the simulations. Dead (D) and live (L) loads (1.0 L + 0.5 D) were applied over sufficient time such that no dynamic effects were excited in the building. The structure under static loading came into equilibrium prior to the removal of any columns. Consecutively, explicit time integration was used to model the post column removal phase. Physics-based simulations were utilized to research the energy flow and behavior of major structural members during progressive collapse propagation or arrest.

\subsection{Building stability}

Whereas plastic resistance plays an important role in the initial response to the localized damage, column buckling controls the global stability of typical steel-framed buildings. Simulated buckling results were compared with results in the literature and verified with high fidelity, numerical simulations, as well as with available empirical results. Teh and Clarke [34] demonstrated that a 
corotational beam formulation with material plasticity is suitable for the simulation of column buckling and post-buckling behavior of typical wide flange sections. The inclusion of geometric imperfections in the range of $L / 1000$ to $L / 3000$ enabled buckling initiation in their numerical models, and resulted in an excellent agreement with laboratory tests conducted on real life columns. This study proposed to introduce the random, normal distributions of crookedness (with $95 \%$ of values within 1/1500 of member length) and out-of-plumbness (with $95 \%$ of values within 1/500 of member length) because these distributions correspond to assembly accuracy and real-life manufacturing imperfections [35].

Consecutively a number of steel columns of various lengths with fixed-fixed, fixed-pinned and fixed-free boundary conditions, comprising a wide spectrum of slenderness ratios, were simulated under increasing axial load. Figure 4 shows a comparison between the simulated buckling loads and AISC empirical buckling curve [29], derived from a large set of experimental results [36]. Good agreement between the numerical and empirical AISC curve confirms the effectiveness of the employed modeling technique.

\section{Results and discussion}

The selected steel building (Figure 1) was subjected to over twenty column removal scenarios in order to investigate the key factors in progressive collapse. Removal of four or more columns typically resulted in a total building collapse. Copious results were generated, but only a representative subset is discussed herein. The case of an arrested collapse and a partial collapse are described to illustrate the key findings of the presented study.

\subsection{Arrested collapse}

Two first story columns A1 and B1 (see Figure 1 for notation) were abruptly removed after quasi-static application of dead and live loads. The deflections generated as the damaged building finds a new equilibrium position are quite large, but the building does not collapse. The final, stable building 
configuration is shown in Figure 5. Once all the released potential energy and the excess of kinetic energy were absorbed by the structure, it reached a stable configuration (Figure 6).

In order to understand the distribution of deformation energy in space, the global energy results were decomposed into contributions from the 'energy zones' (Figure 7). Energy distribution among the prescribed zones showed that the energy was absorbed and dissipated only in the proximity of the removed columns (Figure 8). External work was in essence transferred to the portion of the building within the limits of zone 2. Deformation energy did not increase noticeably in zones 2-3, 3-4 and 4-5.

In order to understand the energy absorption during collapse, frame members were organized into groups according to their structural function and orientation: beams spanning in the $x$-direction, beams oriented in the $y$-direction and columns. The external work was essentially transferred into deformation energy of beams, especially to those oriented in the $y$-direction (see Figure 9, and Figure 5 for $x$ - and $y$ orientations). Since relative share of internal energy of columns decreased, columns did not play an important role in the first phase of the building response to the localized failure. Energy transferred to beams was mainly converted into irreversible plastic energy (Figure 10). The spread of inelasticity in the beams was concentrated in the plastic hinge regions.

The energy-based observation on the importance of beams in the initial response to localized damage is consistent with forensic evidence and state-of-the-art in structural engineering. Historically, connections have been identified as one of the contributing factors of Ronan Point building collapse [1]. Subsequently to the collapse of Ronan Point a number of ductility requirements for connections resurfaced. Vlassis et al. [37] further confirmed that susceptibility to progressive collapse is mainly related to the span sizes of the beams as well as the joint details used at the beam ends. Figure 9 and Figure 10 confirm the ductility provisions because most of the released gravitational energy localized in the form of irreversible, plastic energy of beams. 
Column deformation energy has not yet been investigated in the context of progressive collapse. In the arrested collapse, columns contributed very little to the dissipation of the released gravity work. The external work was stored in columns as elastic energy, which can be theoretically retrieved during unloading (Figure 11). However, the presence of the permanent loads resulting from tributary areas of slabs, self-weight and additional live loads, continuously resting on the columns at all times, prevented any noticeable unloading. Thus, no significant energy sloshing or redistribution was noticed because the released gravitational energy was in principle localized and dissipated via plastic, irreversible deformations of the beams.

Nevertheless, for approx. 2.5 [s], energy stored in columns oscillated due to the effects of the sudden gravity loading. The columns temporary stored and released the energy before arriving to the stable configuration. The dynamic, increased deformation energy demand on a column may lead to buckling and further collapse propagation. This transient energy demand cannot be captured by the static alternate load path analysis because static analysis provides the information pertaining to the final stable state, the energy level at $3[\mathrm{~s}]$ in Figure 11.

\subsection{Partial collapse}

To this point the proposed energy based analysis independently confirmed the observations of the engineering community that beams and connections play a significant role in arresting collapse propagation. In order to provide insights beyond the conventional engineering knowledge, a partial collapse case is discussed, hereinafter. The removal of three columns, one more than in the arrested collapse case, resulted in the collapse of four bays encompassing the shaded zone in Figure 12. Transient dynamic effects triggered buckling failure of column B2 in the first story (Figure 13B).

A buckling instability occurs when the reduction in force resistance is accompanied by the increase in displacement. Thus, both force and displacement need to be tracked at every time increment 
and the combined data are checked against a stability criterion. It should be noted that force or displacement alone are not sufficient to identify the column instability. A buckling failure is defined as a sustained instability leading to material failure in plastic hinges, and column failure. A buckling failure should not be confused with buckling instability. Buckling failure is a final column state, but buckling instability is a state at the current instance of time. An unstable column, with decreasing force resistance and increasing displacements, may potentially reach a stable state when dynamic load reduces its magnitude. Thus, an unstable column may potentially reach a stable state, with a reduced post-buckling, residual capacity. A force limit between stable and unstable states can be identified in the case of monotonic loading by employing the above criterion. However, such a force value is only relevant for this particular monotonic loading. It may not be applicable to complicated, dynamic load paths with multiple stable and unstable transitions.

Following the failure of column B2, the shear connections between column $\mathrm{C} 1$ and the adjacent beams and slabs failed (Figure 13C). Therefore, the collapse propagation in the $x$-direction was halted. The collapse cut-off can be attributed to the strong perimeter columns C1, D1, E1 and F1, as well as, beams in the moment resisting line " $\mathrm{A}$ " (Figure 12), which were sufficiently robust to withstand the demands from the failing bays. Once four bays encompassing AC13 impacted the base layer, the demand on the adjacent bays decreased and the building achieved a final, stable configuration.

The deformation energy of the system increased more than twenty times (Figure 14). Significant levels of kinetic energy were observed during the building response to the columns removal. The kinetic energy began to shrink as bays with removed columns impacted the ground, and the kinetic energy was transformed into deformation related, internal energy of beams and columns. When the kinetic energy vanished from the system, the building reached a stable state of partial collapse. 
A relative deformation energy allocation between the beams in the $x$ - and $y$-directions, as well as, columns is shown in Figure 15. Initially, the energy absorption mechanism was very similar to the arrested collapse case (Figure 9), because mainly beams spanning in the y-direction were dissipating the external work. However, once the beams became "overwhelmed" with the released gravitational energy, columns began to take up more energy. The buckling failure of the first story column B2 increased the relative participation of columns in energy dissipation. However, the energy dissipation and absorption in columns originated not only from the buckling deformations of the first story column B2, but also from columns around the perimeter of the failing bays. For example, the surviving column $\mathrm{C} 2$ in the first story exhibited an increase of both elastic and plastic energy, but it did not fail (Figure 16).

Under more severe localized failure, resistance of beams was not sufficient to arrest the collapse, and columns were affected by the transient dynamic response of the building. The dissipation of external work was characterized by the following sequence of mechanisms: 1) localized beam plasticity, 2) column buckling, and 3) crushing of beams during impact.

\subsection{Irreversible damage}

Deformation work done on a column can be decomposed into irreversible plastic and elastic energy. Such decomposition is useful in understanding of how much irreversible change, and thus damage, is done to columns. Elastic-plastic decomposition was applied to the survivor column C2 in order to understand its dynamic behavior during the collapse (Figure 16). An abrupt increase in deformation energy was noticeable after $1.5 \mathrm{~s}$ and this point corresponds to the loss of stability. The column was slightly bouncing up and down as indicated by its level of elastic energy that was oscillating with a half period of approximately $0.25 \mathrm{~s}$. Column arrived at the stable energy state after $3 \mathrm{~s}$, when the elastic energy and the total deformation energy level down. The final stable state was characterized by 
noticeable irreversible deformation energy and thus permanent damage. This column should be further evaluated, and perhaps retrofitted.

Energy decomposition into irreversible and elastic energy was also applied to the failed B2 column. Failure was preceded with the column loss of stability after $0.5 \mathrm{~s}$ (Figure 17). Unlike C2 column, B2 did not arrive to a stable, post-buckling state. It should be noted that elastic energy does not instantaneously disappear after the column's loss of stability. On the contrary, elastic energy decreases gradually with the increase of the total deformation energy in the post-buckling mode (Figure 17). Excessive plastic deformations in the plastic hinge regions resulted in material failure, which was numerically realized by element deletion (so called element erosion). Thus, once plastic hinges failed, and their corresponding elements were removed from numerical analysis, the elastic energy dropped to zero and the column could not resist loads beyond this state.

Both the failed and surviving columns experienced the same peak dynamic force nearing the buckling limit (Figure 18). Whereas, column B2 failed, column C2 was unloaded up to the level of the new, nontransient load resting on the column. The permanent load supported by $\mathrm{C} 2$ column increased from 1400 $\mathrm{kN}$ in the intact structure to $2000 \mathrm{kN}$ after partial collapse. However, peak dynamic forces neared the buckling limit of $2600 \mathrm{kN}$ and the column momentarily lost its stability only to reach a stable state in the post-buckling phase. Unlike column C2 that was loaded and unloaded, no oscillatory behavior was observed in column B2. The force displacement behavior indicated a monotonic loading path into postbuckling, and up to the column collapse. Column B2 experienced a sustained instability, which resulted in the material failure in the plastic hinges, and column failure.

The peak dynamic resistance forces were practically identical, but the deformation work done on both columns was significantly different. Column C2 was irreversibly deformed, but it did not collapse. The deformation energy time history (Figure 16) signaled the change in the column behavior from the pre- 
buckling to the post-buckling, and finally to the permanently deformed configuration. Figure 16 and Figure 17 demonstrate that the deformation energy may be more representative of the fundamental changes in structural behavior than the peak dynamic forces alone.

\subsection{Post-collapse building stability}

Further analysis is devoted to the post-collapse building stability in order to determine its safety against further collapse. Whereas, failed members and partial collapse can be easily identified by visual inspection of simulation results, overstressed but survived columns are not effortlessly detected. Actually, significant post-processing effort is required to assess the post-collapse building safety. It is imperative to identify columns in the post-buckling stage because they may pose a threat to the safety of the structure. Unfortunately, their presence is not obvious at the first glance.

Traditionally, a column's state is defined in the force domain. The buckling force defines the limit between the stable and unstable states. This approach to column stability originates from quasi-static load tests conducted in the middle of the 20th century [38][39]. However, the loading applied to the column during progressive collapse is transient and varying in time. Thus, a column can be temporary overloaded and buckle but does not fail because it has a residual post-buckling resistance, which may suffice to support the permanent, non-transient loading. Pre-buckling and post-buckling stable states have virtually the same internal axial forces equal to the permanent, tributary loading (Figure 19). However, both configurations have distinctly different internal deformation energies. Actually, buckling results in a significant energy increase, which is several times greater than the initial, pre-buckling internal energy stored (Figure 20). Buckling failure increases the internal energy dramatically beyond the original energy levels.

Whereas, the column buckling force limit is prescribed by codes, and broadly used, the energy corresponding to buckling is rarely calculated. The energy buckling limit and its associated post-buckling 
dissipative energy capacity can be estimated, provided that force-displacement characteristic of the column is known [21]. The limiting buckling energy was calculated by means of finite element analysis using LS-DYNA [26]. Numerical simulations of axial column loading were carried out for all the sections employed in this study. Initial curvature and eccentricity were introduced to initiate the buckling in accordance with the handbook of construction tolerances [35]. A buckling instability was identified when the reduction in the force resistance was accompanied by the increase in displacement. Numerically obtained buckling loads were in a good agreement with AISC [29] empirical values. The deformation energy was obtained from the integration of the force-displacement time history under monotonic loading. The energy corresponding to the first occurrence of instability was selected as the buckling onset instability limit, which separates the desired column behavior from the post-buckling, residual column resistance. The deformation energy corresponding to the buckling onset of each column was retrieved from the single column simulations, and saved as its respective buckling energy limit.

These limiting, buckling energies were employed to investigate the global building stability in the aftermath of the columns removal. The inertia and frequency content of a loading function affects buckling force. However, energy limit states are not sensitive to loading rates, unlike deformation and force limits. A numerical buckling instability of a typical W12x58 column, subjected to monotonic axial loading, is first encountered at $2670 \mathrm{kN}$. However, as the loading rate exceeds $40000 \mathrm{kN} / \mathrm{s}$, the simulated buckling force increases up to $3600 \mathrm{kN}$ (a $35 \%$ increase) due to inertial effects. However, the same inertial effects reduce the column's displacements. Thus, the deformation energy corresponding to the instability initiation changes only slightly from 7.5 to $7.9 \mathrm{~kJ}$ (a $5 \%$ increase). This leads to the observation that the deformation energy is far less sensitive to the loading rate than force or displacement due to counteracting inertial effects on the force resistance and the corresponding displacements. Therefore, the deformation energy is a more robust instability measure under dynamic loading conditions. In addition, progressive collapse may introduce additional end-forces (e.g. 
moments). These forces contribute to the deformation energy, and are automatically accounted for by the deformation energy limit.

The buckling energy limit was employed to evaluate the stability of the building after partial collapse (shown in Figure 13). Analyses of column energies revealed that the deformation energy in the first story column B2 exceeded its characteristic buckling energy threshold (Figure 21). Second and third story columns B2 were also overloaded. This energy based examination was consistent with visual inspection of the simulation results (Figure 13). Column B2 buckled first and collapsed shortly afterwards.

The deformation energy plot (Figure 21) provided further insights into the building stability. First story column A3 played an important role in preventing the collapse propagation, as inferred from its elevated energy level. Although it absorbed more energy than other columns, its buckling energy limit was not exceeded due to larger W14x99 shape. On the other hand, the first story column $\mathrm{C} 2$, the weaker W12x58 section, was affected by the partial collapse and slabs tearing. Column C2 exceeded its respective buckling energy threshold and buckled, but did not fail (Figure 18 and Figure 21).

The building condition after partial collapse is summarized in Figure 22. The energy based analysis of the structural stability identified that the first story column A3 played a pivotal role in preventing further collapse propagation. Although this column approached its buckling limit, it did not buckle (Figure 21). Another first story column C2 exceeded the buckling energy limit, buckled but did not fail. In order to increase the safety margin against the real life variations and random effects, both columns $A 3$ and $C 2$ should be upgraded.

Since progressive collapse is a highly nonlinear phenomenon, the strengthening of the selected columns may potentially have unintended consequences and cause overloading of different columns. The new 
design with upgraded columns $A 3$ and $C 2$ should be subjected again to the prescribed column removal scenarios in order to ensure that columns' deformation energy is below the buckling energy limits.

\section{Conclusions}

The sudden release of the gravitational energy will always result in motions and kinetic energy. The ability of any structure to arrest the collapse hinges on its capacity to dissipate the kinetic energy, and thus to phase out transient motions. In addition, the structure must also maintain sufficient force resistance in order to support its permanent, non-transient loads, in spite of the structural deterioration resulting from the transient, dynamic effects.

A column that survives a collapse-initiating event responds dynamically before eventually coming to rest. A column could be temporarily loaded beyond its buckling load, but it may not fail if that load is removed before the column can respond. The post-buckling resistance may suffice to support the permanent, non-transient loading. The proposed deformation energy limit is helpful in the identification of columns, which experience transient instability, but do not fail.

In conventional engineering, structural members do not only carry the loads but also dampen the motions resulting from abnormal loadings. Unfortunately, the beneficial dissipation of the released gravity work also diminishes their load carrying capacity. Thus, future studies may need to focus on energy dissipation through the use of friction, fluid dampers, and metal-based honeycomb devices to dissipate the kinetic energy, but without compromising the load carrying members.

\section{Acknowledgment}

The authors gratefully acknowledge the support from the US Army Engineer Research Development Center (ERDC) Vicksburg, MS, for this study. 


\section{References}

[1] Pearson C, Delatte N. Ronan Point Apartment Tower Collapse and its Effect on Building Codes. J Performance of Constructed Facilities 2005; 19(2):172-77.

[2] Hinman EE, Hammond DJ. Lessons from the Oklahoma City Bombing: Defensive Design Techniques, American Society of Civil Engineers, ASCE Press, New York, 1997.

[3] Mlakar PF, Dusenberry D, Harris J. The Pentagon Building Performance Report, American Society of Civil Engineers, Structural Engineering Institute Publication 2002.

[4] Palmisano F, Vitone A, Vitone C, Vitone V. Collapse of the Giotto Avenue Building in Foggia. Structural Engineering International 2007; 17(2):166-71.

[5] Pearson C, Delatte N. Ronan Point Apartment Tower Collapse and its Effect on Building Codes. J Performance of Constructed Facilities 2005; 19(2):172-77.

[6] Osteraas, JD. Murrah Building Bombing Revisited: A Qualitative Assessment of Blast Damage and Collapse Patterns. Journal of Performance of Constructed Facilities 2006: 20(4):330-335.

[7] Krauthammer T, Modern Protective structures. CRC Press, 2008.

[8] Grierson DE, Xu L, Liu Y. Progressive-Failure Analysis of Buildings Subjected to Abnormal Loading. Computer-Aided Civil and Infrastructure Engineering 2005;20:155-171.

[9] Izzuddin A, Vlassis AG, Elghazouli AY, Nethercot DA. Progressive collapse of multi-storey buildings due to sudden column loss - Part I: Simplified assessment framework. Engineering Structures 2008;30:1308-1318.

[10] Schafer BW, Bajpai P. Stability degradation and redundancy in damaged structures. Engineering Structures 2005;27:1642-1651.

[11] Kaewkulchai G, Williamson EB. Beam element formulation and solution procedure for dynamic progressive collapse analysis. Computers and Structures 2004;82:639-51. 
[12] Krauthammer T, Lim J, Choi H J, Elfahal M. Evaluation of Computational Approaches for Progressive Collapse and Integrated Munitions Effects Assessment, PTC-TR-002-2004. Protective Technology Center (Civil Engineering), Pennsylvania State University 2004.

[13] Powell GP, Progressive Collapse; Case Studies using Nonlinear Analysis. Metropolis and beyond proceedings of the 2005 Structures Congress and the 2005 Forensic Engineering Symposium. New York, NY: Reston, Va. ;American Society of Civil Engineers (ASCE). April 20-24, 2005.

[14] Menchel K, Massart TJ, Rammer Y, Bouillard P, Comparison and Study of Different Progressive Collapse Simulation Techniques for RC Structures, Journal of Structural Engineering 2009;135(6):685-697.

[15] Khandelwal K, El-Tawil S, Kunnath S, Lew HS. Macromodel-Based Simulation of Progressive Collapse: Steel Frame Structures. Journal of Structural Engineering 2008;134(7):1070-78.

[16] Khandelwal, K., El-Tawil, S., Sadek, F. Progressive collapse analysis of seismically designed steel braced frames. Journal of Constructional Steel Research 2009;65:699-708.

[17] Sadek F, Main JA, Lew HS, Robert SD, Chiarito V. Testing and Analysis of Steel Beam-Column Assemblies under Column Removal Scenarios. Proceedings of the 2009 Structures Congress - Don't Mess with Structural Engineers: Expanding Our Role, Reston, VA: American Society of Civil Engineers 2009; pp.1708-17.

[18] Kwasniewski L. Nonlinear dynamic simulations of progressive collapse for a multistory building. Engineering Structures 2010;32:1223-1235.

[19] Szyniszewski ST, Krauthammer T, Yim HC. Energy Flow Based Progressive Collapse Studies of Moment Resisting Steel Framed Buildings. Final Report to U.S. Army ERDC, CIPPS-TR-003-2008, Center for Infrastructure Protection and Physical Security, University of Florida, January 2009. 
[20] Szyniszewski S. Dynamic Energy Based Method for Progressive Collapse Analysis. Proceedings of the 2009 Structures Congress - Don't Mess with Structural Engineers: Expanding Our Role, Austin, TX, April 30-May 2, 2009; Reston, VA: American Society of Civil Engineers 2009.

[21] Smyth AW, Gjelsvik A. Energy Capacity Criterion for the Design of Columns against Collapse. ASCE Journal of Engineering Mechanics 2006;132(6):594-99.

[22] Loizeaux M, Osborn, AE. Progressive Collapse - An Implosion Contractor's Stock in Trade. Journal of Performance of Constructed Facilities 2006;20(4):391-402.

[23] Bažant ZP, Verdure M. Mechanics of Progressive Collapse: Learning from World Trade Center and Building Demolitions. Journal of Engineering Mechanics 2007; 133(3):308-19.

[24] Seffen KA. Progressive Collapse of the World Trade Center: Simple Analysis. Journal of Engineering Mechanics 2008;134(2):125-132.

[25] Delatte NJ. Beyond Failure: Forensic Case Studies for Civil Engineers, American Society of Civil Engineers, Reston, Virginia: ASCE Press, 2009.

[26] Hallquist J. LS-DYNA: theory manual. Livermore, California: Lawrence Software Technology Corporation, 2006.

[27] Gupta A, Krawinkler H. Behavior of ductile SMRFs at various seismic hazard levels. Journal of Structural Engineering 2000;126(1):98-107.

[28] Foley CM, Martin K, Schneeman C. Robustness in structural steel framing systems. Rep. No. MUCEEN-SE-06-01 Milwaukee, Wis: Marquette Univ, 2006.

[29] American Institute of Steel Construction. Steel Construction Manual, 13th Ed, Chicago, IL: AISC, 2006. 
[30] Sabuwala T, Linzell D, Krauthammer T. Finite element analysis of steel beam to column connections subjected to blast loads. International Journal of Impact Engineering 2005; 31:861-876. This was not a very good paper, since the work had various limitations that the first two authors did not pay attention to. I did not see the material until after it was published, and it was too late to correct the results.

[31] Yim, HC, Krauthammer T. Mathematical-Mechanical Model of WUF-B Connection under Monotonic Load. AISC Engineering Journal 2010; 47(2):71-79.

[32] Lewitt CW, Chesson E, Munse WH. Restraint characteristics of flexible riveted and bolted beam-tocolumn connections. Engineering Experiment Station. Bulletin 500. University of Illinois, Urbana, 1969.

[33] Liu R, Davison B, Tyas A. A Study of Progressive Collapse in Multi-Story Frames. Metropolis and beyond proceedings of the 2005 Structures Congress and the 2005 Forensic Engineering Symposium, New York, NY; Reston, VA: American Society of Civil Engineers 2005.

[34] Teh LH, Clarke MJ. Plastic-Zone Analysis of 3D Steel Frames using Beam Elements. Journal of Structural Engineering 1999;125(11):1328-1337.

[35] Ballast DK. Handbook of Construction Tolerances. New York: McGraw-Hill, 1994.

[36] Hall DH. Proposed Steel Column Strength Criteria. Journal of Structural Division ASCE 1981;107(4):649-670.

[37] Vlassis AG, Izzuddin BA, Elghazouli AY, Nethercot DA. Progressive collapse of multi-storey buildings due to sudden column loss-Part II: Application. Engineering Structures 2008;30:1424-38.

[38] SSRC Centrally Loaded Column Research Inventory. University of Missouri-Rolla: Structural Stability Research Council, February 2003.

[39] Hoff NJ, Nardo SV, Erickson B. An Experimental Investigation of the Process of Buckling Columns. Proceedings of the Society for Experimental Stress Analysis, XIII No.1, 1955;67-76. 


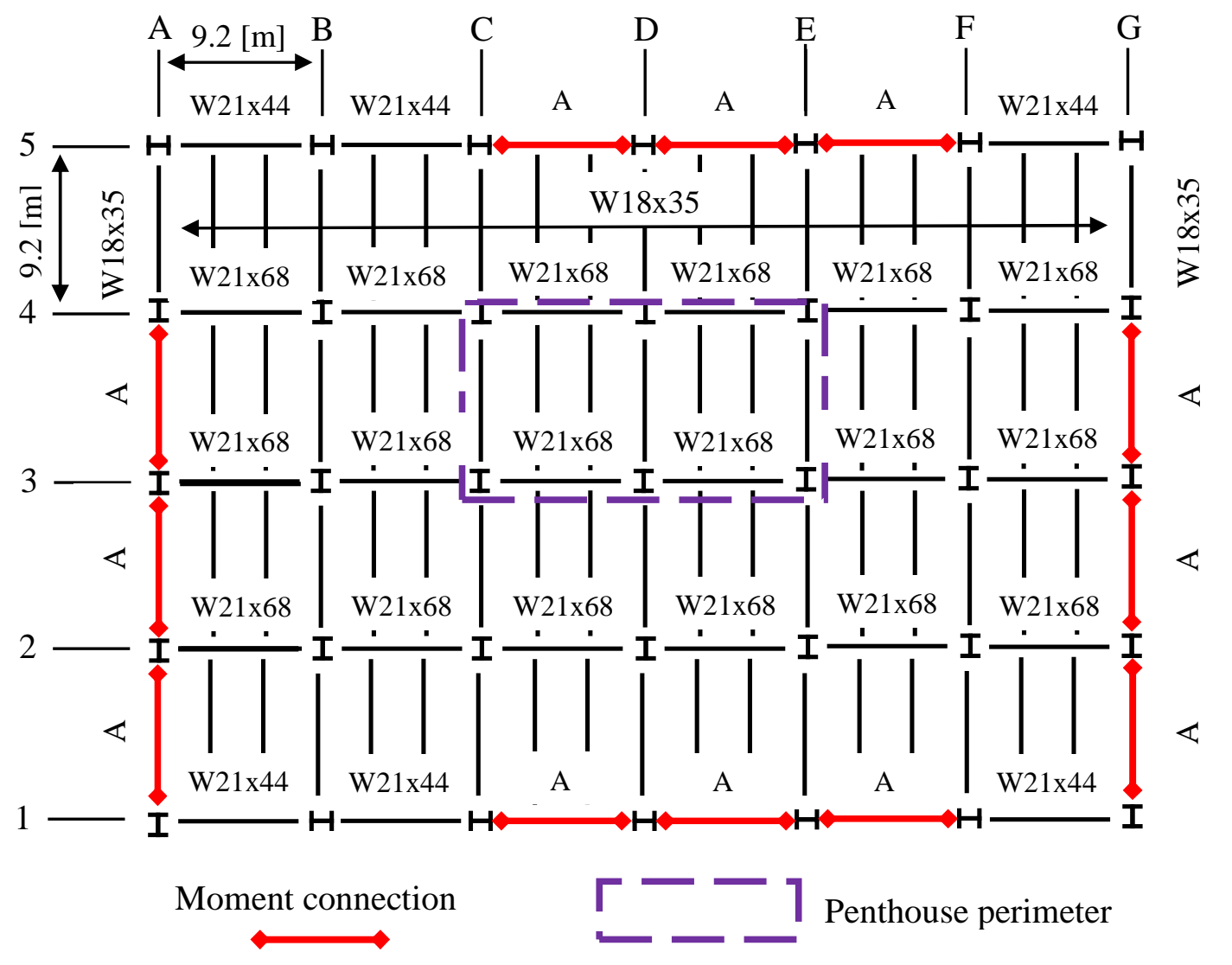

Figure 1. Framing plan of the investigated, representative steel building

Table 1. Beams with moment resisting connections designated with "A"

\begin{tabular}{llll}
\hline Floor & 2 & 3 & roof \\
\hline Beam "A" & W18x35 & W21×57 & W21×62
\end{tabular}

Table 2. Steel profiles of columns

\begin{tabular}{|c|c|c|c|c|c|c|c|}
\hline & A & B & $\mathrm{C}$ & D & $\mathrm{E}$ & $\mathrm{F}$ & G \\
\hline 5 & W12x58 & W12x58 & W14x74 & W14x99 & W14x99 & W14x74 & W12x58 \\
\hline 4 & $\mathrm{~W} 14 \times 74$ & $\mathrm{~W} 12 \times 58$ & $\overline{\mathrm{W}} 1 \overline{2 \times} 6 \overline{5}$ & $\overline{\mathrm{W}} 1 \overline{2 \times} 7 \overline{2}$ & $\overline{\mathrm{W}} 1 \overline{2 \times} 6 \overline{5}$ & W12x58 & $\mathrm{W} 14 \times 74$ \\
\hline 3 & W14x99 & W12x58 & W $12 \times 65$ & $\mathrm{~W} 12 \times 72$ & $\mathrm{~W} 12 \times 65$ & W12x58 & W14x99 \\
\hline 2 & W14x99 & W12x58 & $\mathrm{W} 12 \times 58$ & $\mathrm{~W} 12 \times \overline{5} 8$ & $\mathrm{~W} 12 \times 58$ & $\mathrm{~W} 12 \times 58$ & W14x99 \\
\hline 1 & $\mathrm{~W} 14 \times 74$ & W12x58 & $\mathrm{W} 14 \times 74$ & W14x99 & W14x99 & W14x74 & $\mathrm{W} 14 \times 74$ \\
\hline
\end{tabular}




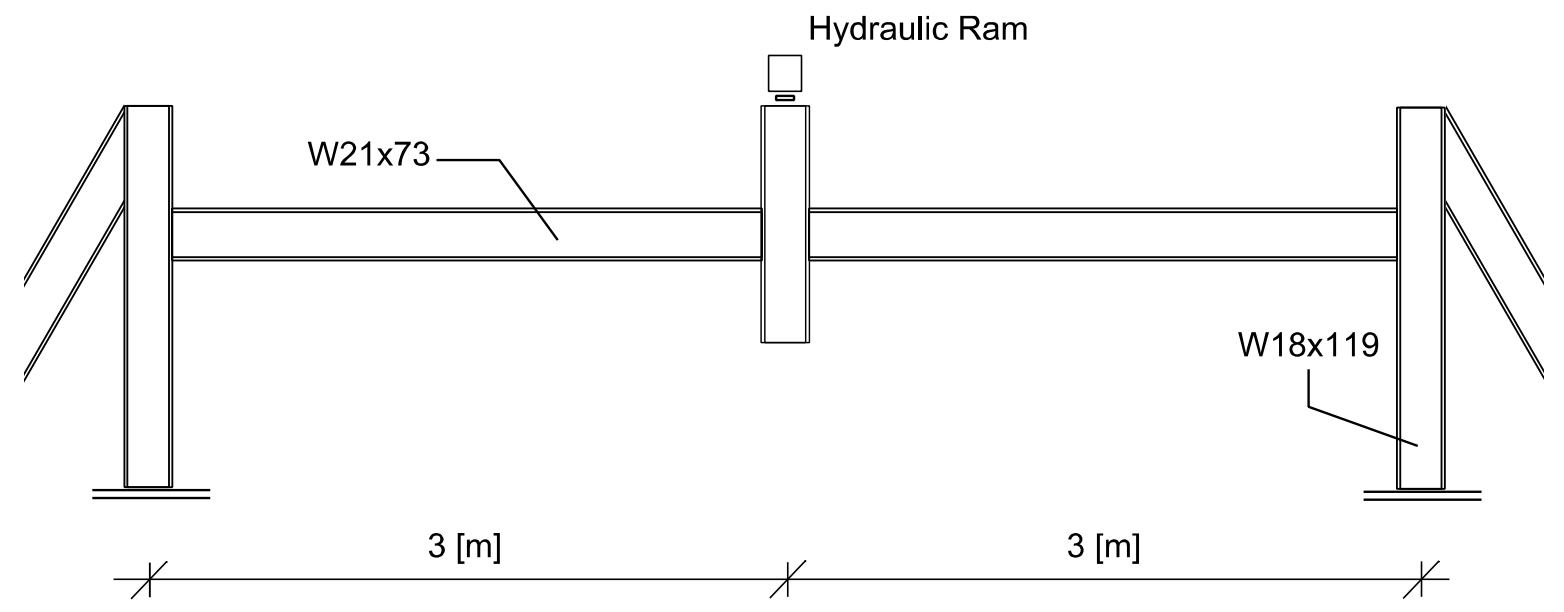

Figure 2. Experimental configuration utilized in NIST testing program [12] 


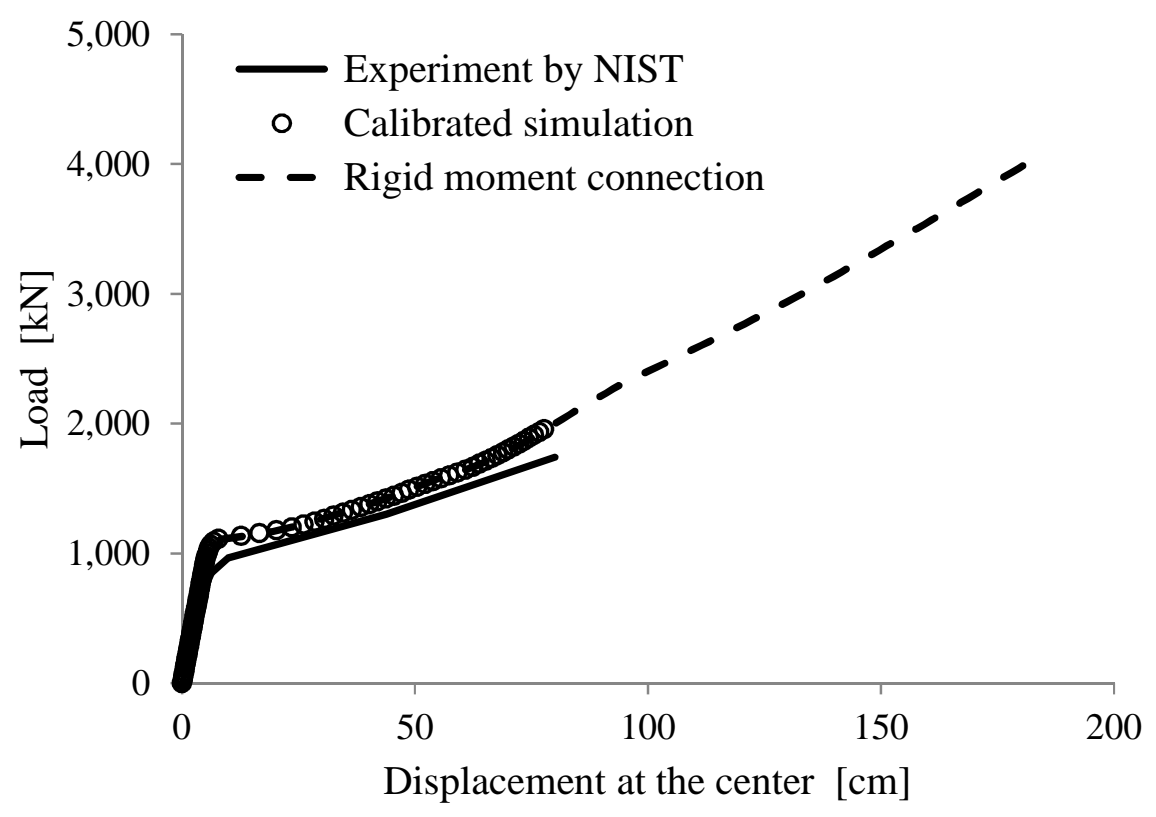

Figure 3. Comparison of NIST experiments [12] with employed calibrated simulations 


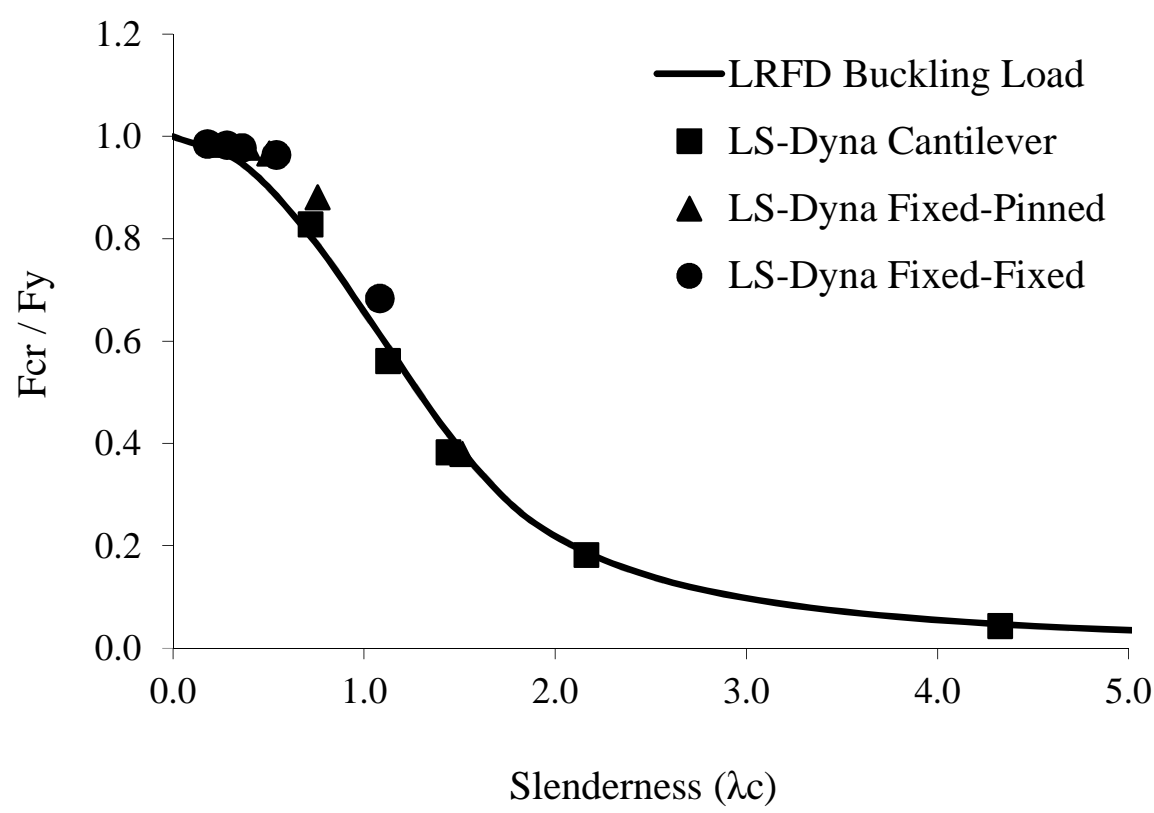

Figure 4. Comparison of simulated buckling loads to the AISC code curve 


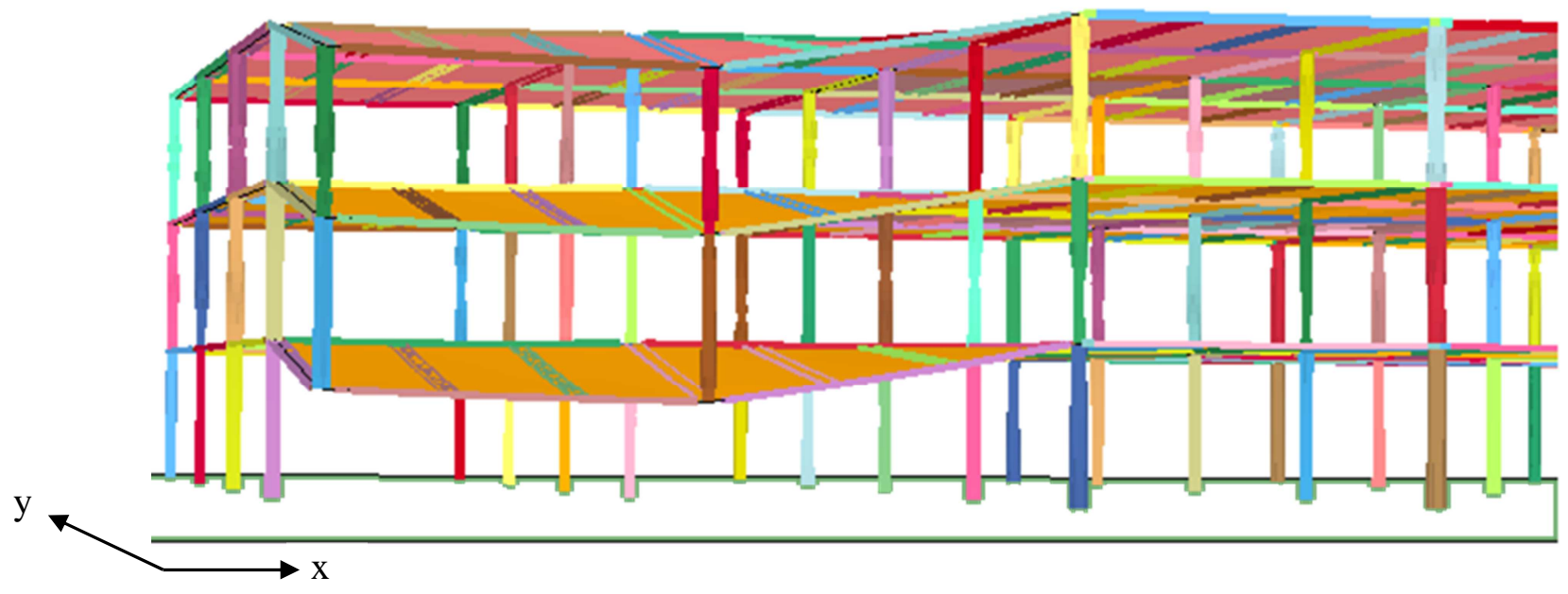

Figure 5. Final deflected configuration of the building after two columns removal 


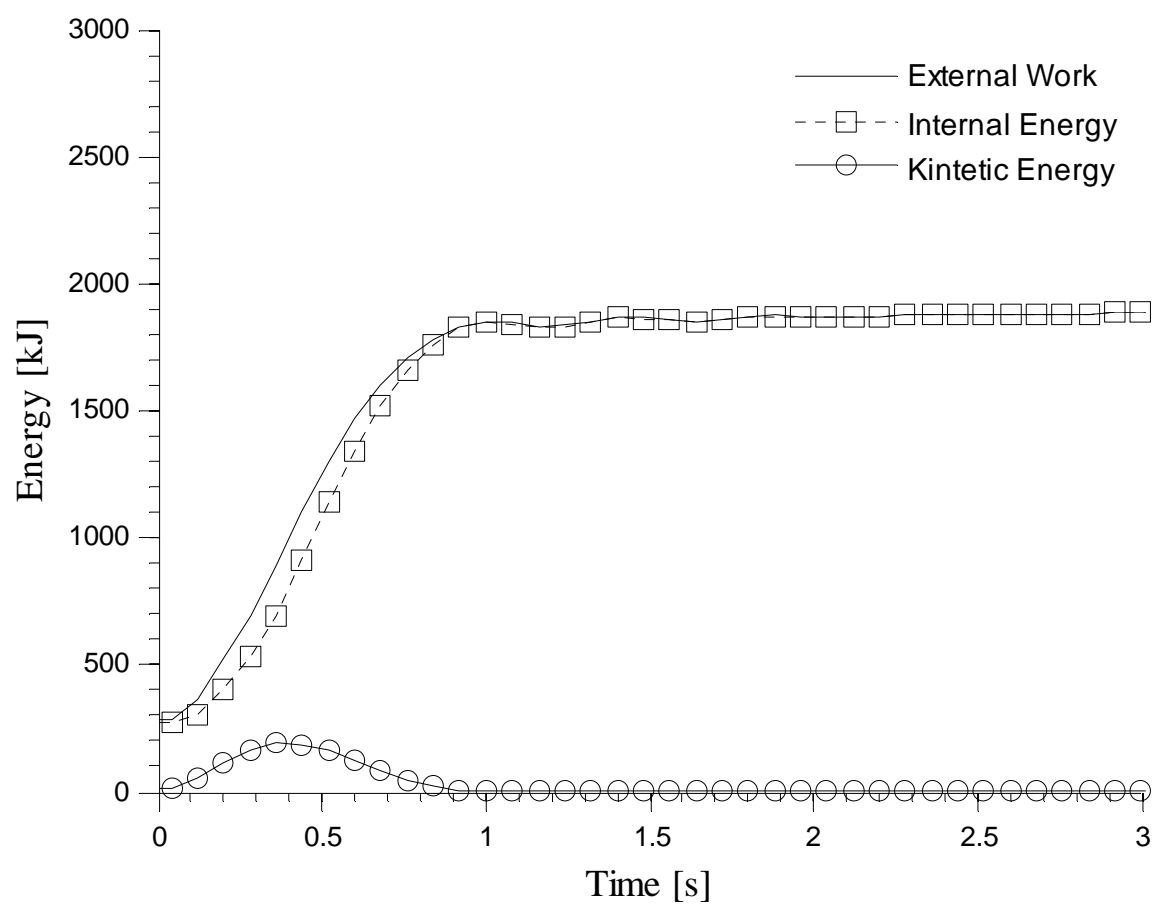

Figure 6. Energy manifestations during building response to the localized damage 


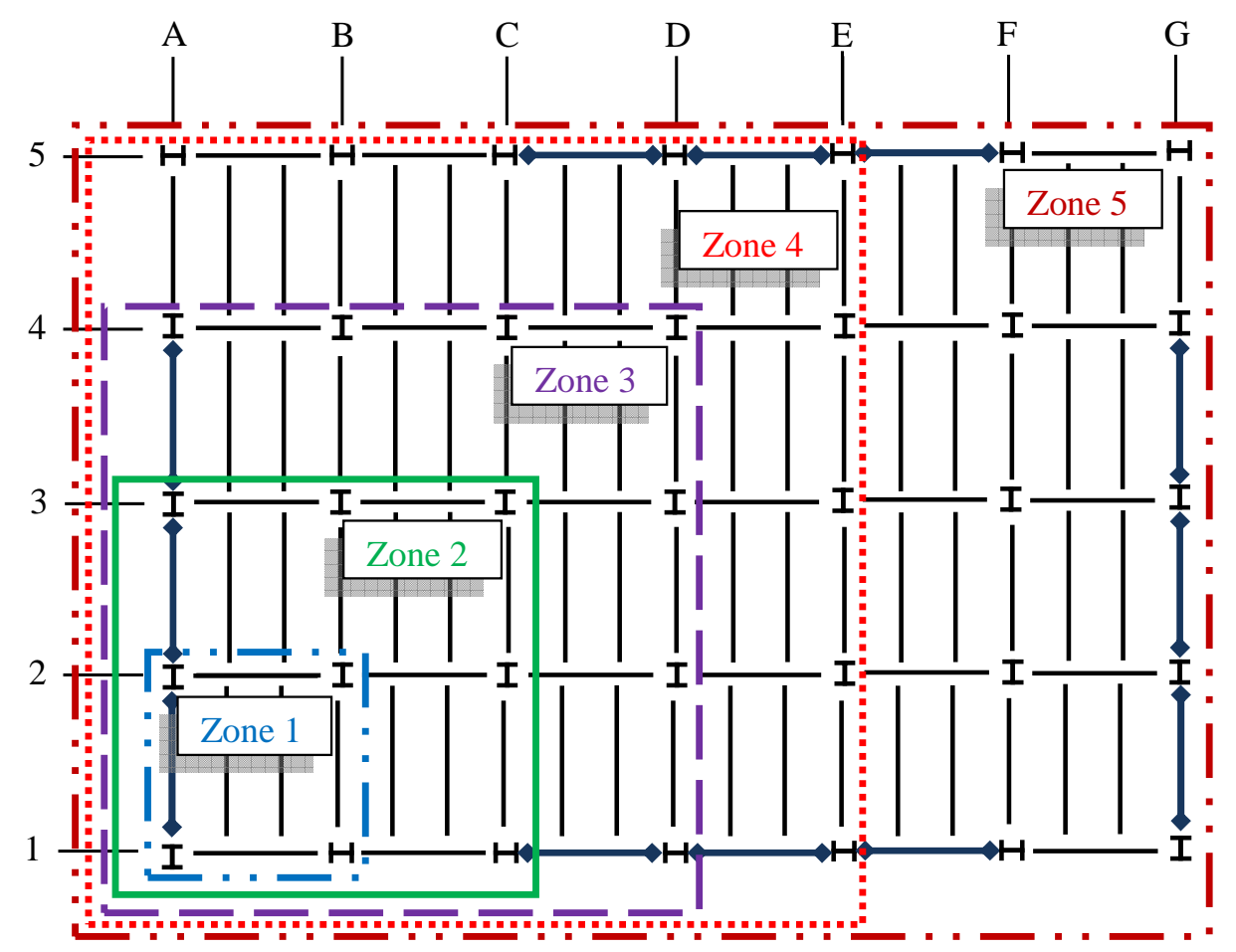

Figure 7. Spatial zones employed to depict the distribution of internal energy in the building 


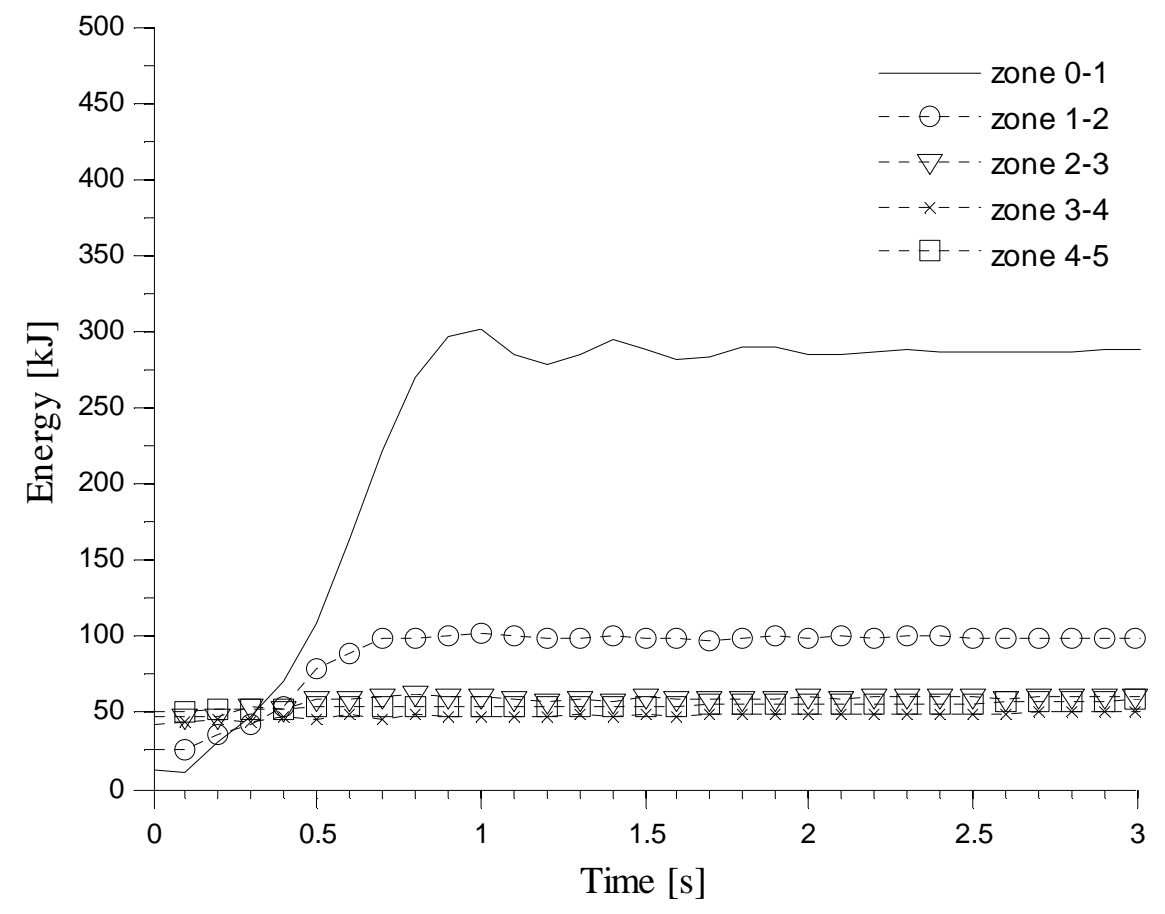

Figure 8. Spatial energy distribution in time for the arrested collapse 


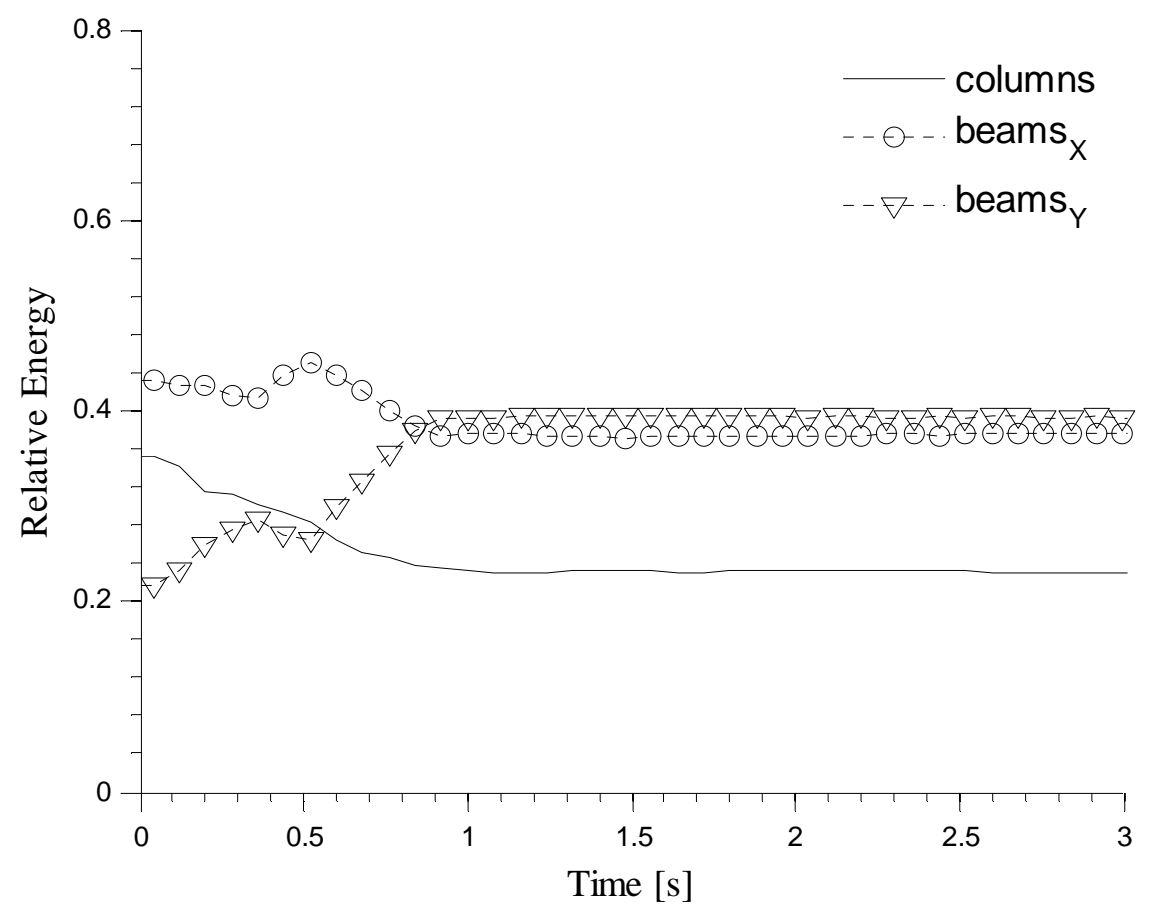

Figure 9. Member contributions in energy absorption and dissipation 


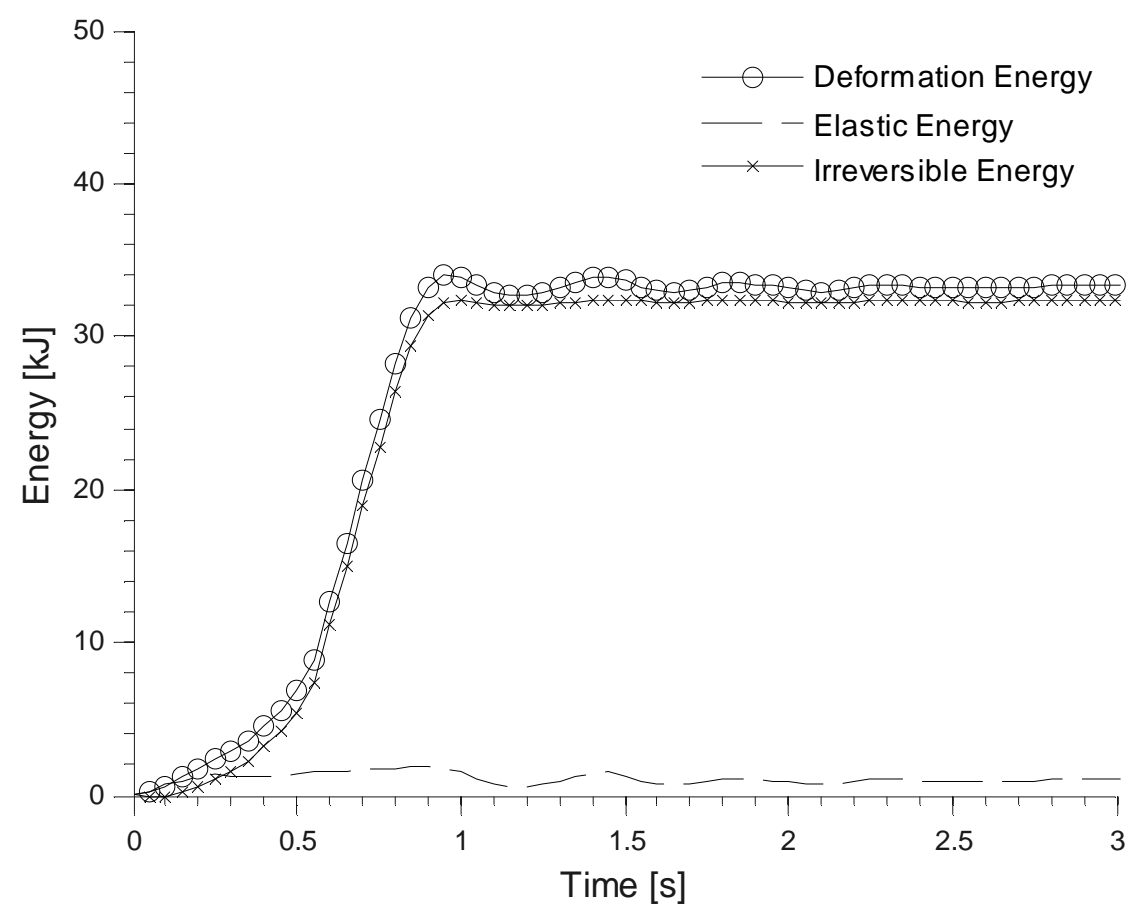

Figure 10. Decomposition of deformation energy in 1st story A1-A2 beam (y-direction) 


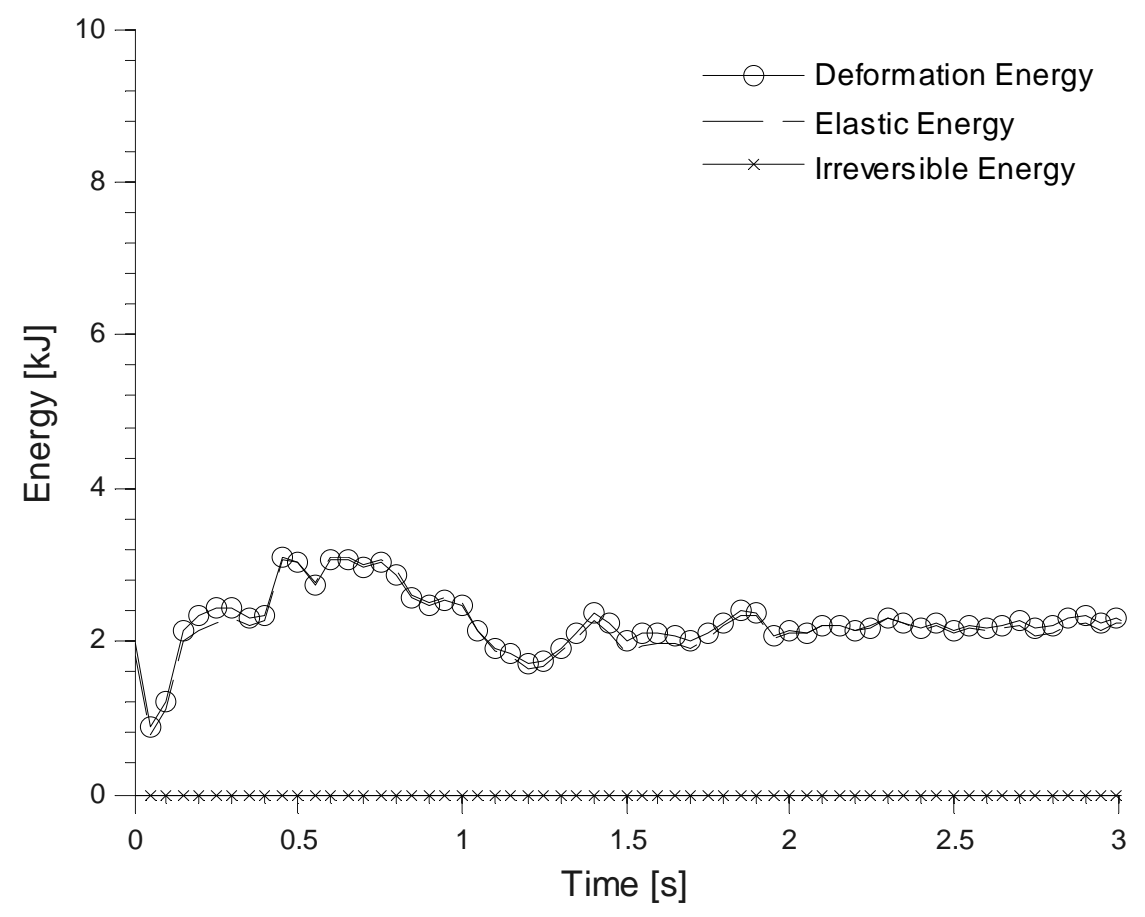

Figure 11. Decomposition of internal energy in B2.1 column 


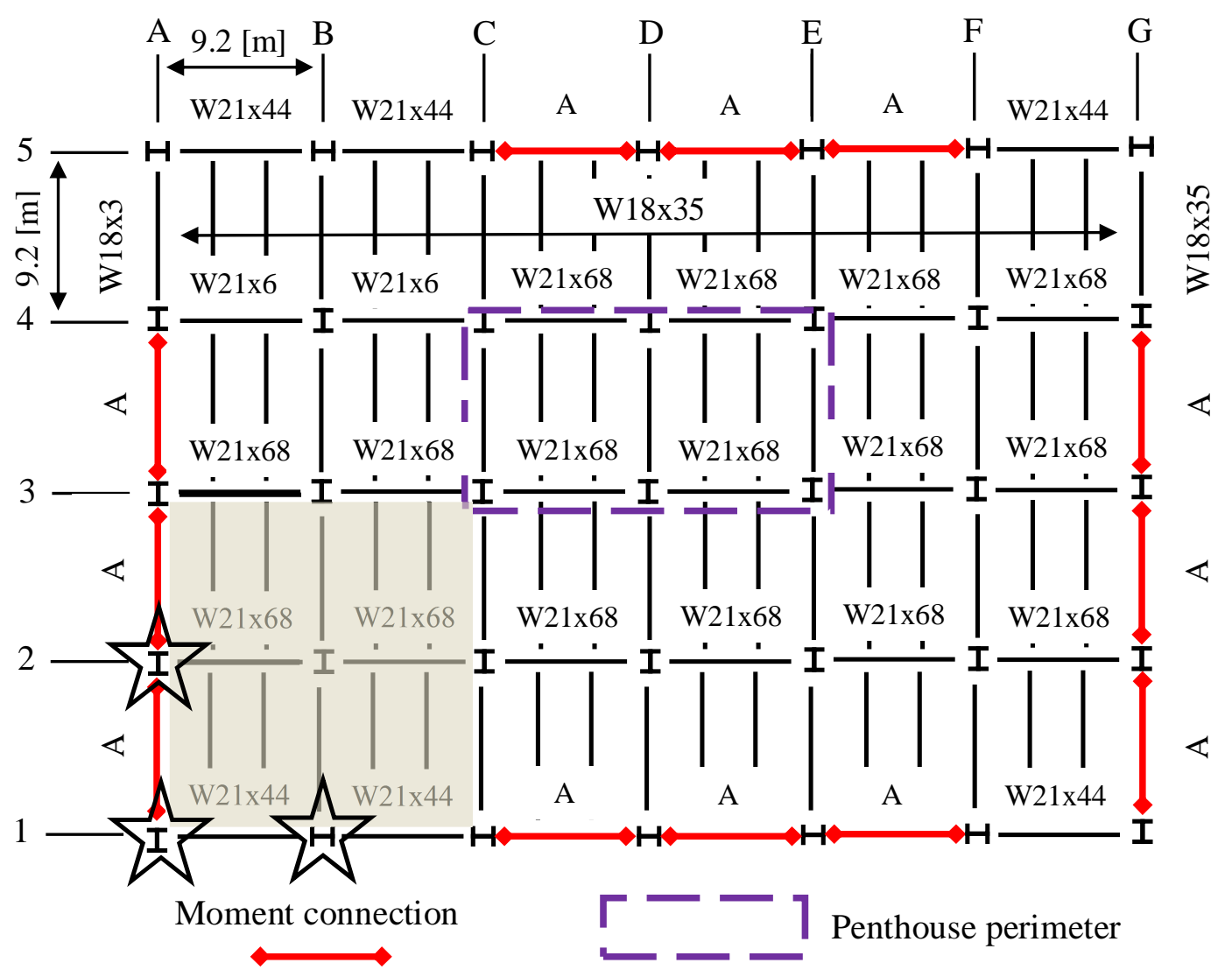

Figure 12. Partial collapse of the investigated, representative steel building 


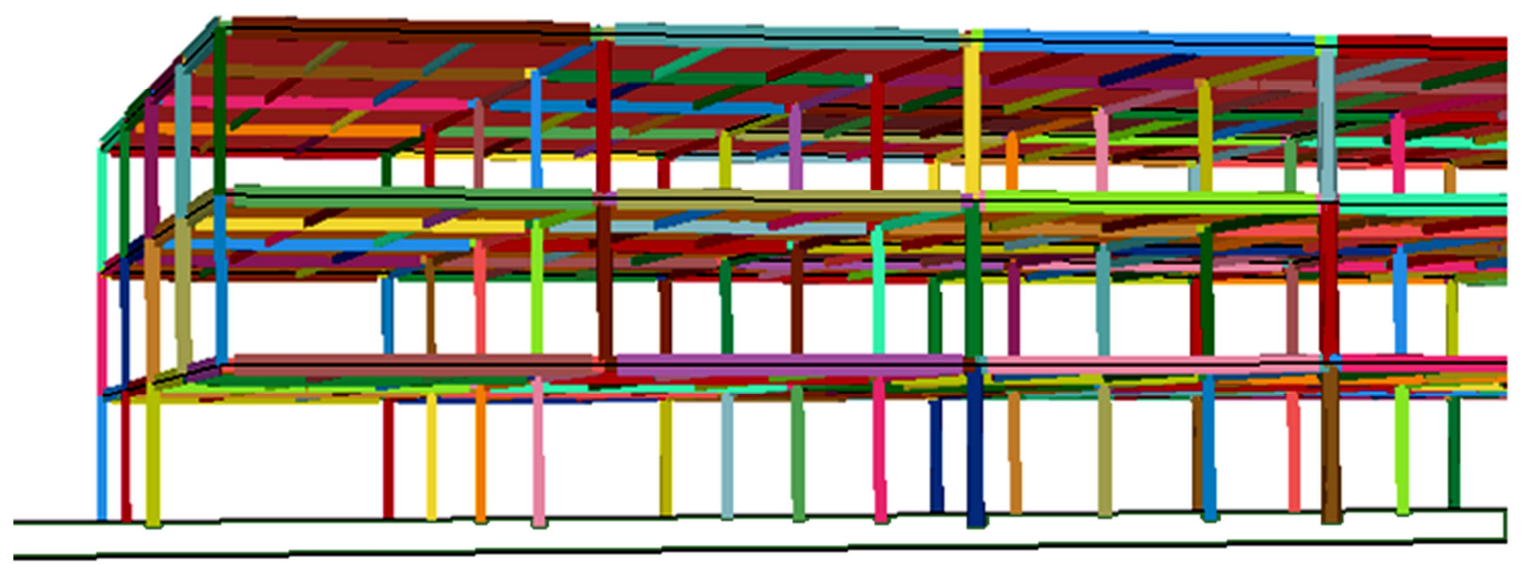

A)

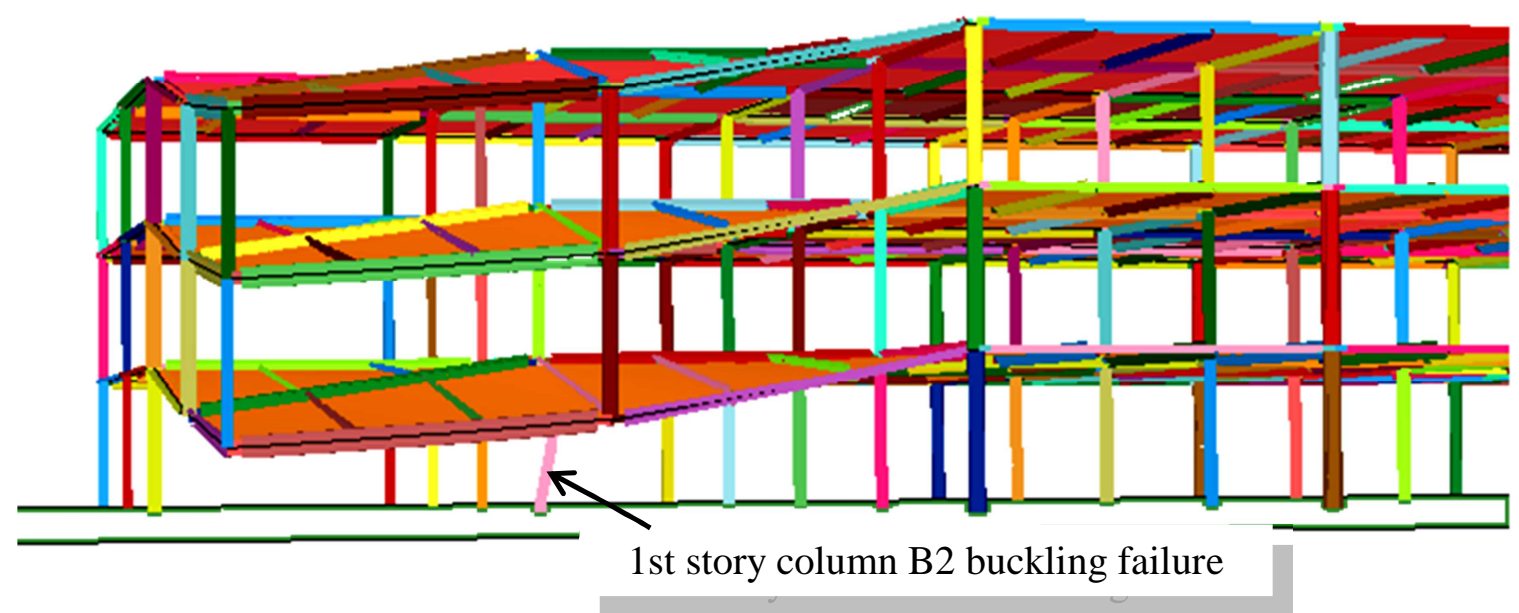

B)

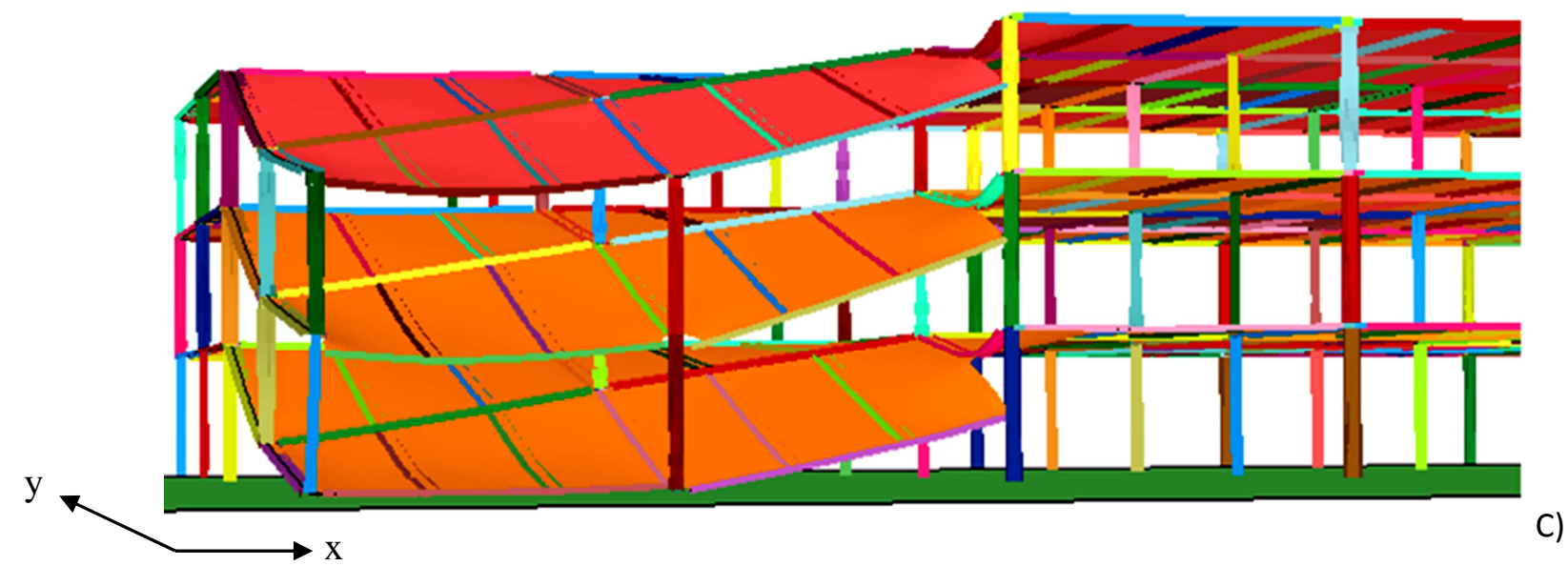

Figure 13. Building response to three columns removal 


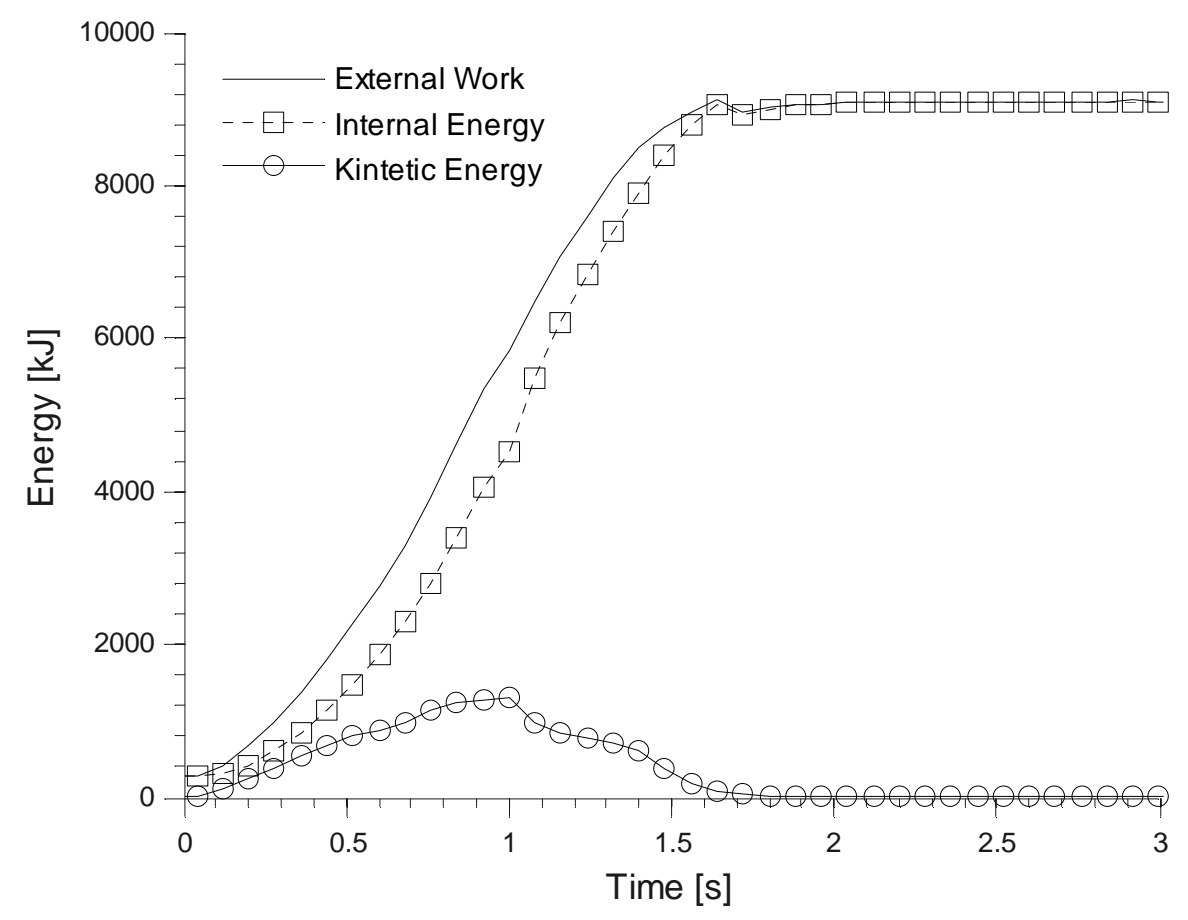

Figure 14. Energy manifestations during building response to the localized damage 


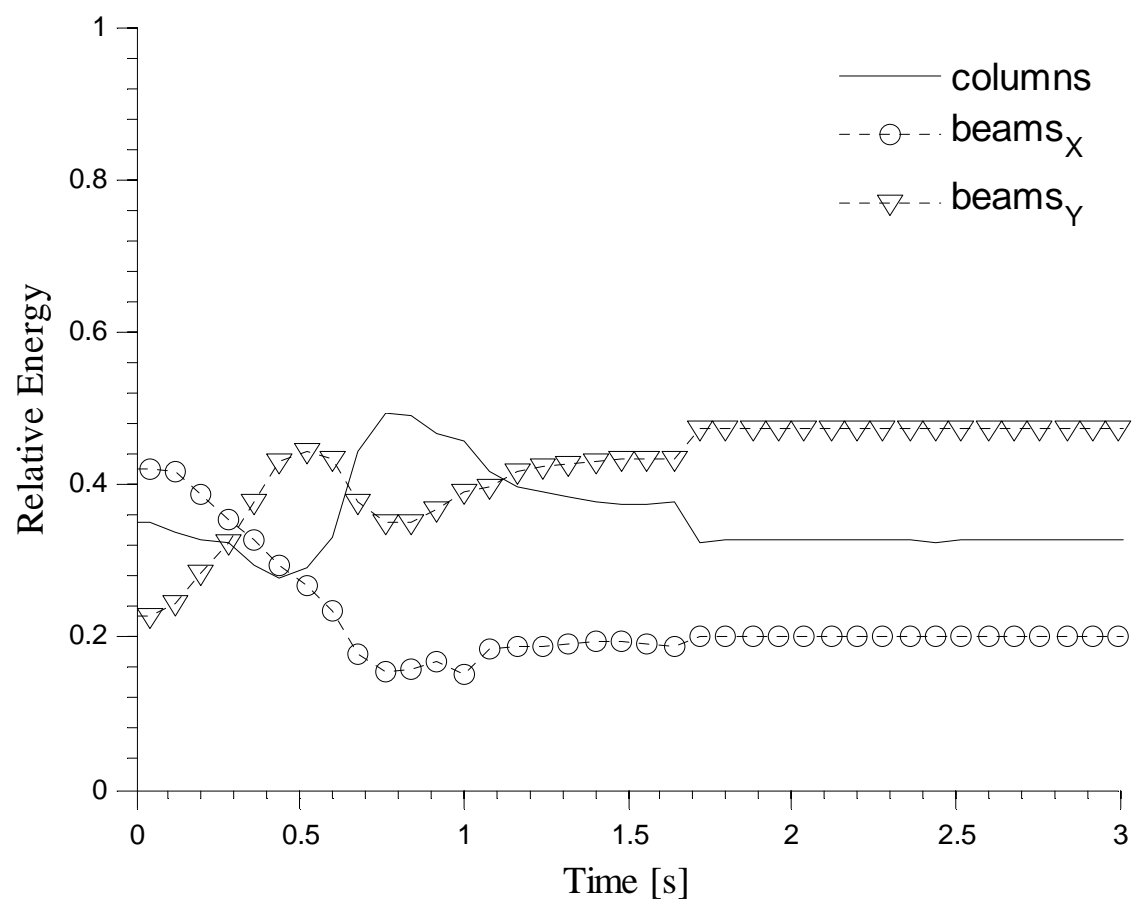

Figure 15. Member contributions in energy absorption and dissipation 


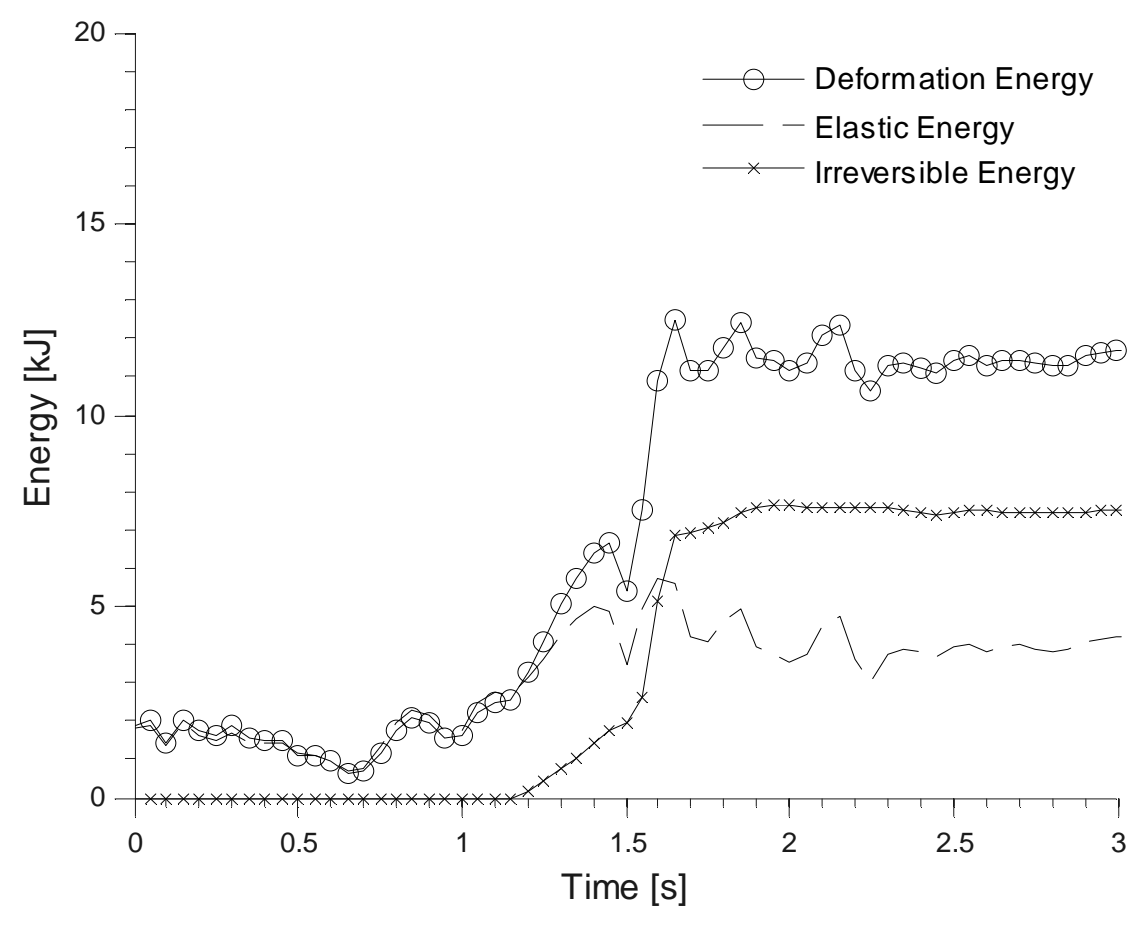

Figure 16. Deformation energy of the surviving column C2 in the first story 


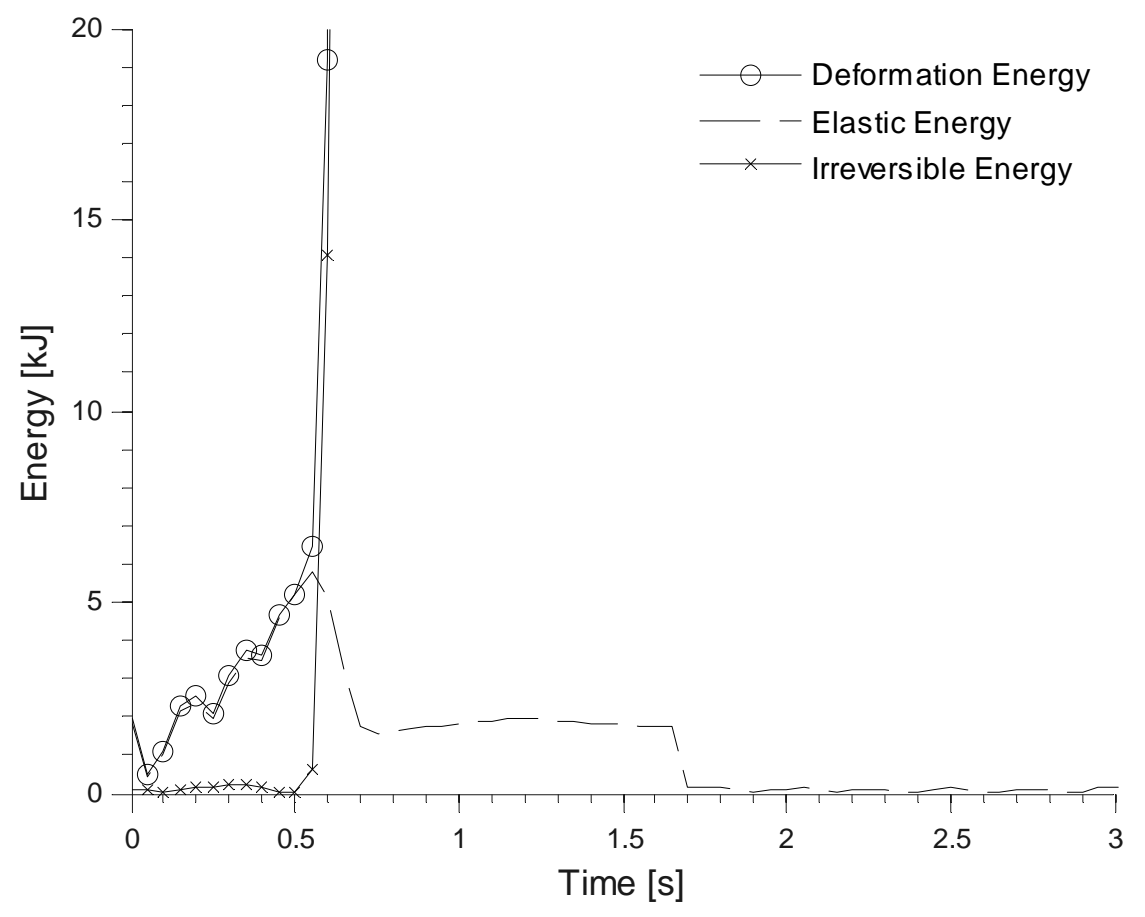

Figure 17. Deformation energy of the collapsed column B2 in the first story 


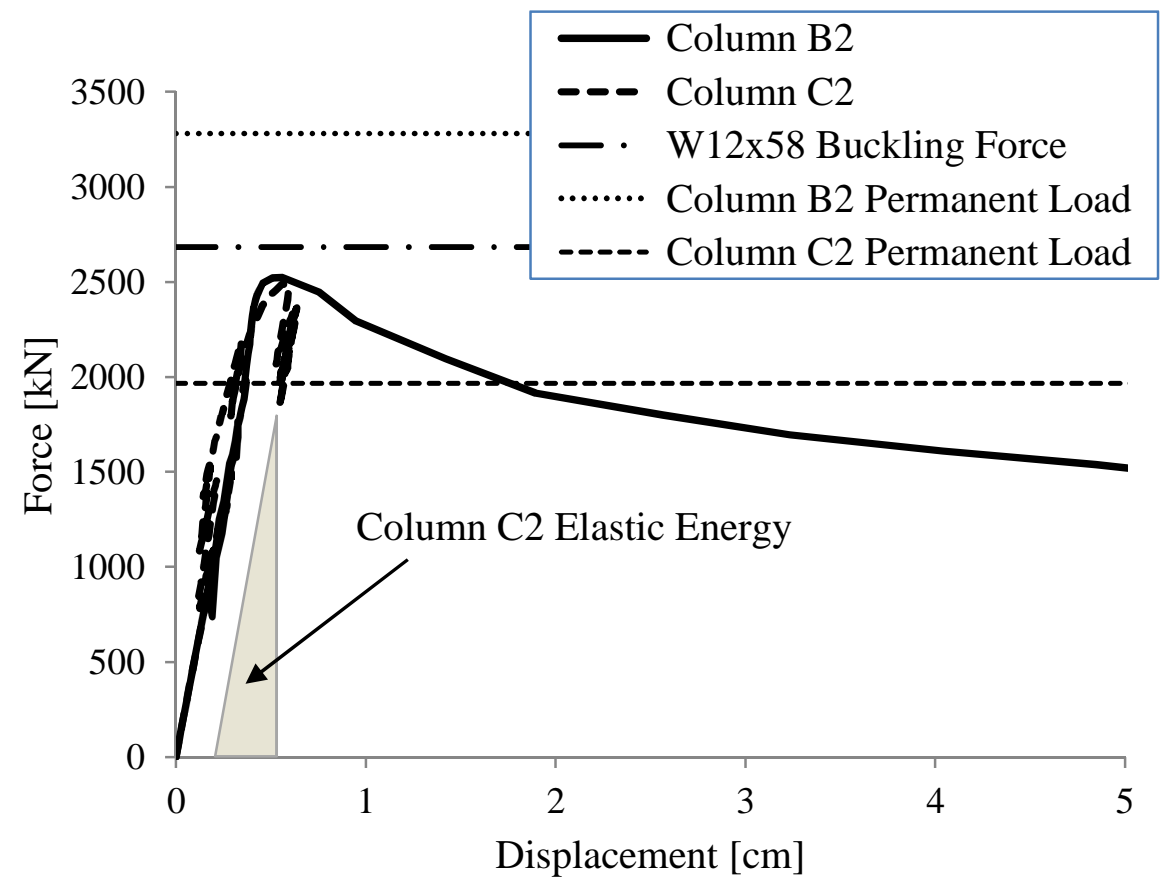

Figure 18. Comparison of axial behavior of the collapsed and the survivor column 


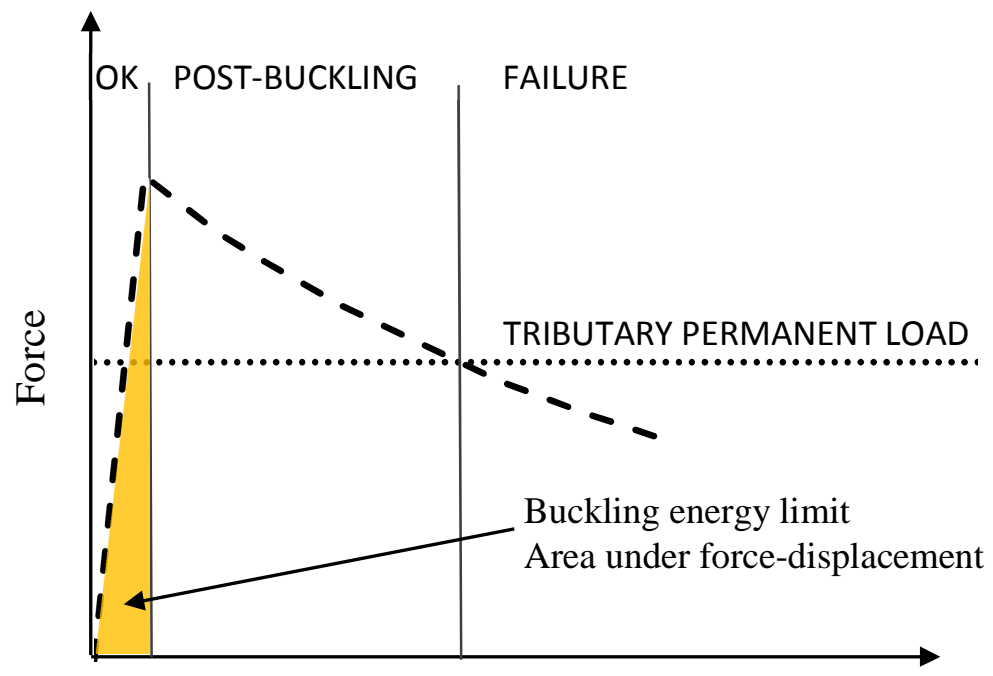

Displacement

Figure 19. Column resistance under monotonic load 


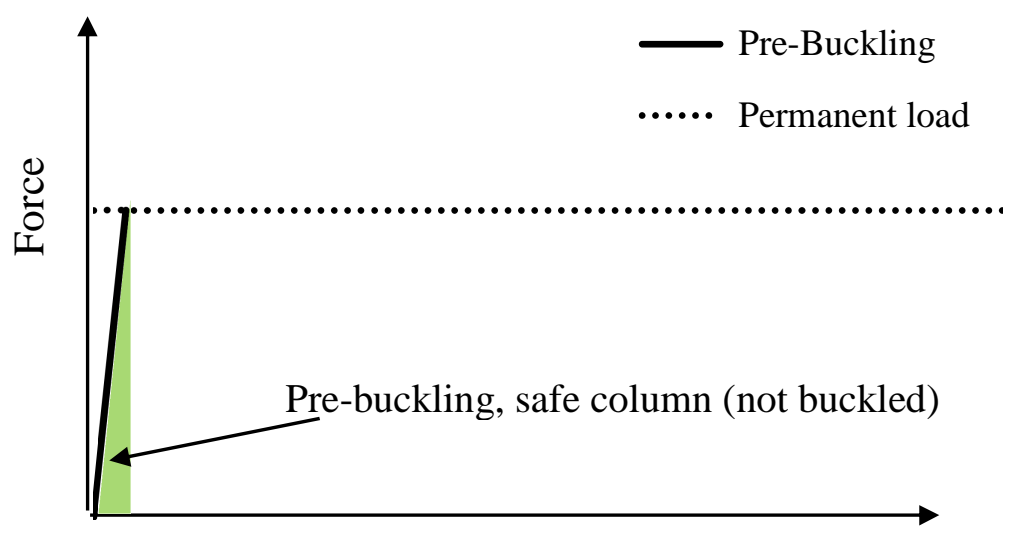

Displacement

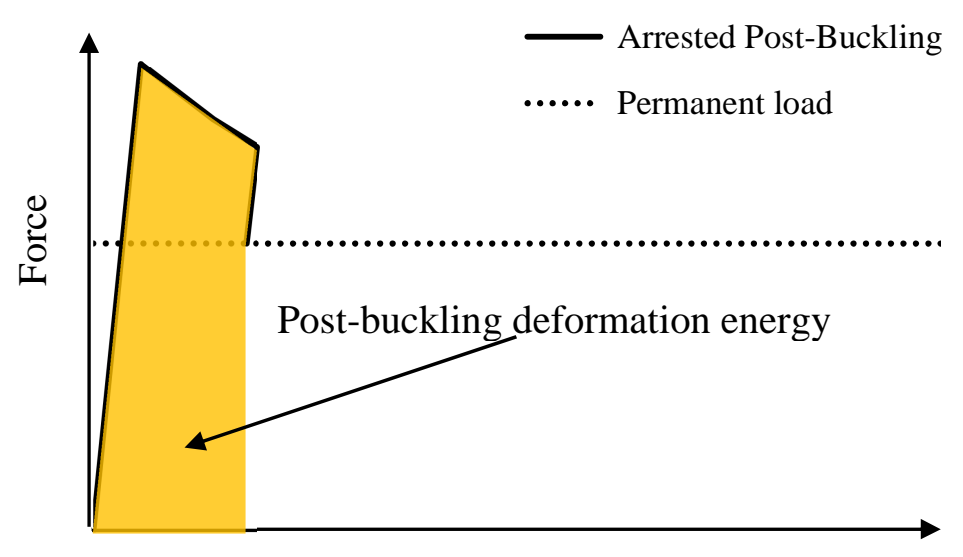

Displacement

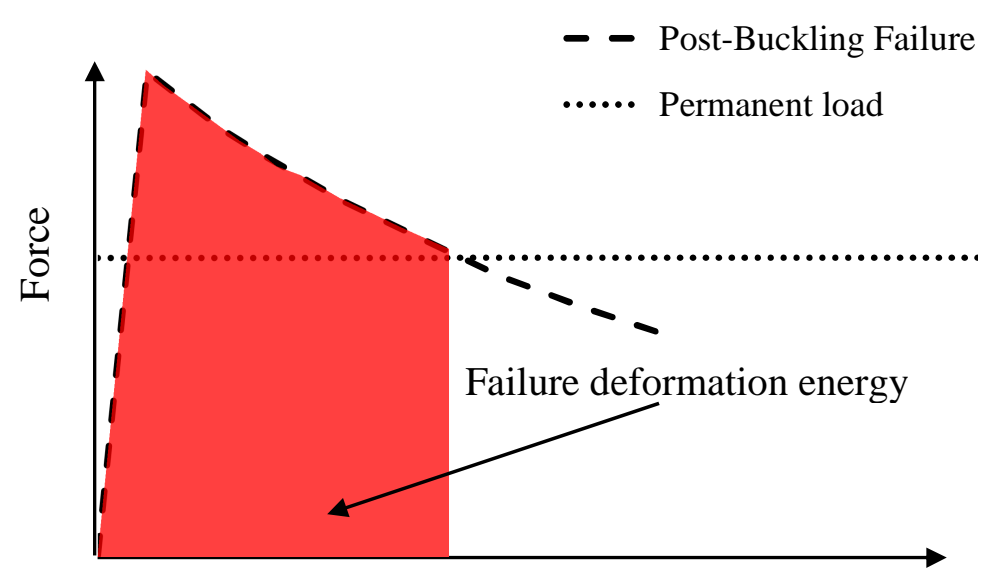

Displacement

Figure 20. Deformation work: A) Pre-Buckling, B) Arrested Post-Buckling and C) Failure 


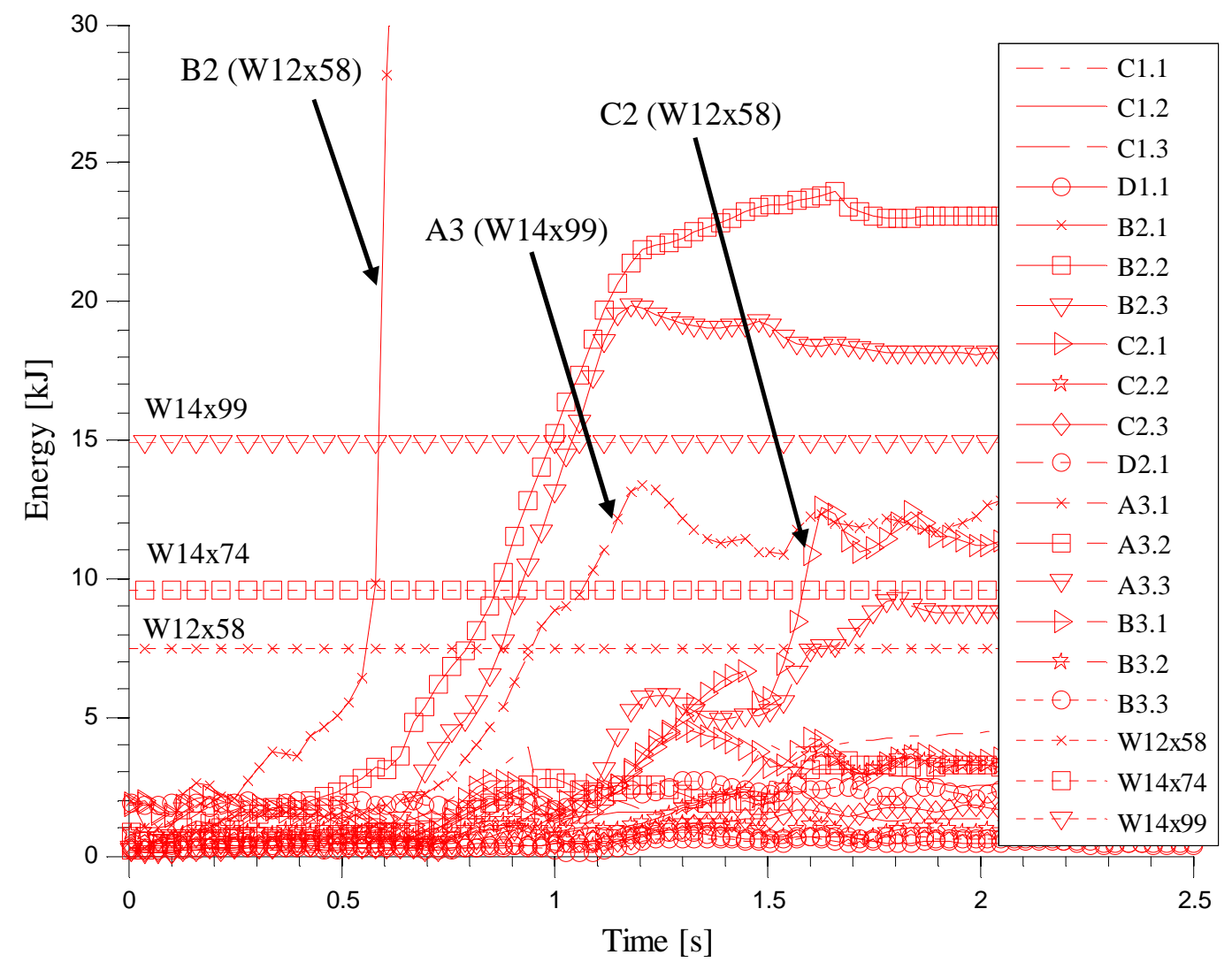

Figure 21. Stability of columns. Energy based analysis 


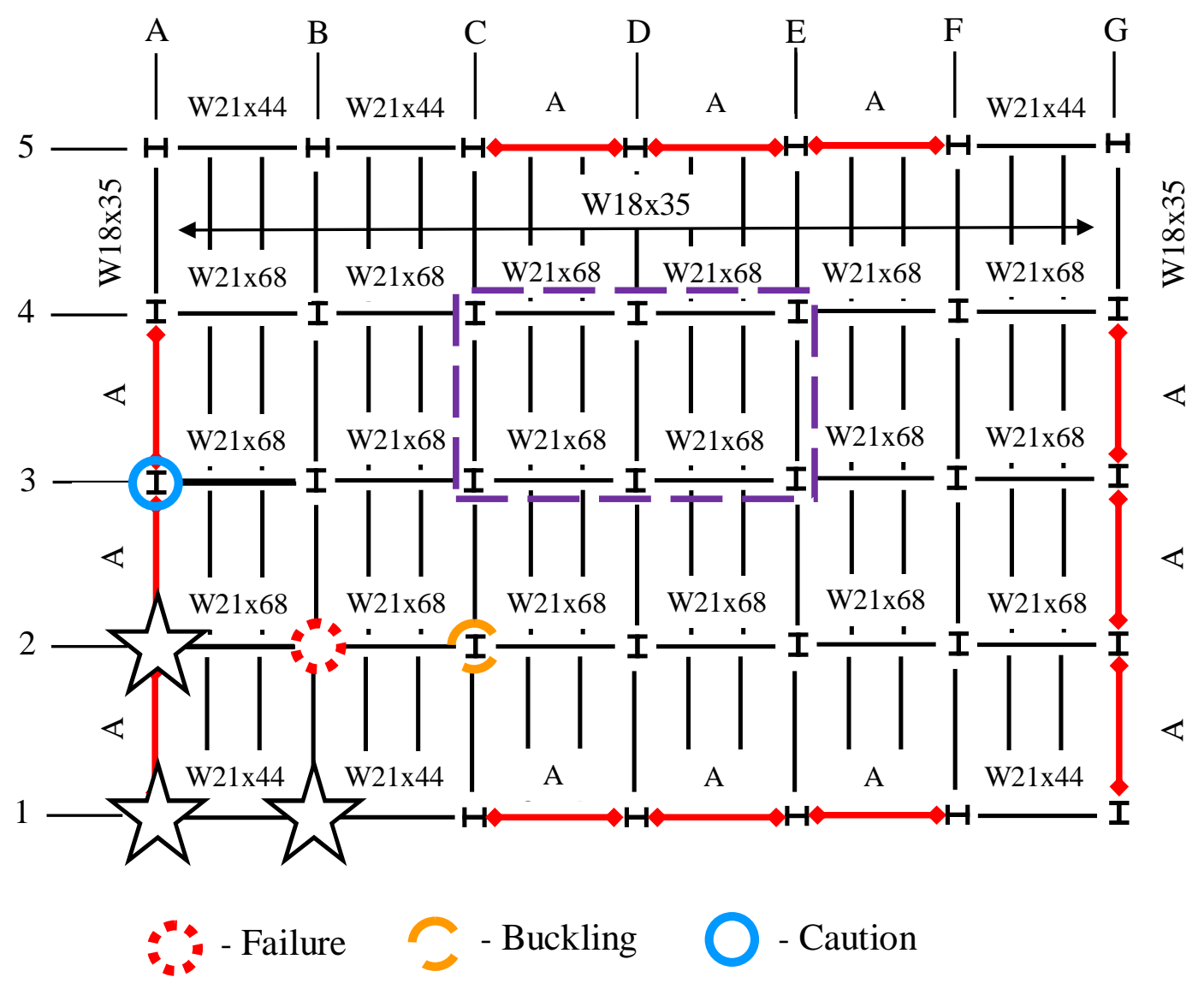

Figure 22. Global building stability 